\title{
Article \\ Synthesis, Purification, and Characterization of Carbon Dots from Non-Activated and Activated Pyrolytic Carbon Black
}

\author{
Reyna Berenice González-González ${ }^{1}$, Lucy Teresa González ${ }^{1}$, Marc Madou ${ }^{2}$ (D) César Leyva-Porras ${ }^{3}$, \\ Sergio Omar Martinez-Chapa ${ }^{1}$ and Alberto Mendoza ${ }^{1, *(1)}$ \\ 1 Escuela de Ingeniería y Ciencias, Tecnologico de Monterrey, Ave. Eugenio Garza Sada 2501, \\ Monterrey 64849, Mexico; reyna.g@tec.mx (R.B.G.-G.); lucy.gonzalez@tec.mx (L.T.G.); \\ smart@tec.mx (S.O.M.-C.) \\ 2 Department of Mechanical and Aerospace Engineering, University of California Irvine, \\ Engineering Gateway 4200, Irvine, CA 92697, USA; mmadou@uci.edu \\ 3 Laboratorio Nacional de Nanotecnología (Nanotech), Centro de Investigación en Materiales \\ Avanzados (CIMAV), Miguel de Cervantes No. 120, Chihuahua 31136, Mexico; cesar.leyva@cimav.edu.mx \\ * Correspondence: mendoza.alberto@tec.mx; Tel.: +52-81-8358-2000 (ext. 5219)
}

\section{check for} updates

Citation: González-González, R.B.

González, L.T.; Madou, M.;

Leyva-Porras, C.;

Martinez-Chapa, S.O.; Mendoza, A.

Synthesis, Purification, and

Characterization of Carbon Dots

from Non-Activated and Activated

Pyrolytic Carbon Black. Nanomaterials

2022, 12, 298. https://doi.org/

10.3390/nano12030298

Academic Editor: Antonios Kelarakis

Received: 14 December 2021

Accepted: 11 January 2022

Published: 18 January 2022

Publisher's Note: MDPI stays neutral with regard to jurisdictional claims in published maps and institutional affiliations.

Copyright: (C) 2022 by the authors. Licensee MDPI, Basel, Switzerland. This article is an open access article distributed under the terms and conditions of the Creative Commons Attribution (CC BY) license (https:// creativecommons.org/licenses/by/ $4.0 /)$.

\begin{abstract}
In this work, carbon dots were created from activated and non-activated pyrolytic carbon black obtained from waste tires, which were then chemically oxidized with $\mathrm{HNO}_{3}$. The effects caused to the carbon dot properties were analyzed in detail through characterization techniques such as ion chromatography; UV-visible, Fourier-transform infrared spectroscopy (FTIR), X-ray photoelectron spectroscopy (XPS), and Raman spectroscopy; $\zeta$ potential; transmission electron microscopy (TEM); and spectrofluorometry. The presence of functional groups on the surface of all carbon dots was revealed by UV-visible, FTIR, XPS, and Raman spectra. The higher oxidation degrees of carbon dots from activated precursors compared to those from nonactivated precursors resulted in differences in photoluminescence (PL) properties such as bathochromic shift, lower intensity, and excitationdependent behavior. The results demonstrate that the use of an activating agent in the recovery of pyrolytic carbon black resulted in carbon dots with different PL properties. In addition, a dialysis methodology is proposed to overcome purification obstacles, finding that $360 \mathrm{~h}$ were required to obtain pure carbon dots synthesized by a chemical oxidation method.
\end{abstract}

Keywords: carbon nanoparticles; top-down synthesis; chemical activation; waste valorization

\section{Introduction}

Carbon dots (CDs), a type of carbon nanomaterial with a size below $10 \mathrm{~nm}$ and a quasi-spherical shape, were discovered in 2004 by Xu et al. [1]. Their intriguing properties, such as biocompatibility and fluorescence, have made them important in a variety of fields [2-7]. They can be synthesized in two ways: bottom-up and top-down. The bottomup approach uses physical and chemical forces to organize atoms or molecules into the desired nanostructure, whereas the top-down approach involves reducing the size of the precursor until it reaches the desired nanostructure [8].

The many potential applications of CDs have led to intense research of environmentally friendly and less expensive synthesis methods [9]. In the case of top-down approaches, the precursors used for nanomaterial synthesis, which are waste carbon-rich materials, have an important role as an excellent option for the conversion of low-value materials into high-value products [10].

In this manner, waste tires could be considered an ideal precursor to produce CDs because nearly $76 \%$ of their composition are carbon-based materials [11], and using a precursor with a low economic value reduces the cost of the process. The feasibility of $\mathrm{CD}$ synthesis from waste tires, on the other hand, is based on the fact that most organic 
compounds containing $\mathrm{C}, \mathrm{H}$, and $\mathrm{O}$, where $\mathrm{H}$ and $\mathrm{O}$ exist in a form that allows dehydration, can be used for CD synthesis [12]. Furthermore, existing commercial waste tire pyrolysis processes could be supplemented with an additional route of high-value products (e.g., CDs), or carbon dots from waste tires could be processed as an additional production line in a conventional pyrolysis plant.

The conceived application of CDs in next-generation devices would require very small quantities of ultrapure $\mathrm{CDs}$ with precisely controllable size, shape, composition, and surface features. Any wet chemical synthesis method is unlikely to produce such high-quality CDs. Such CDs must be manufactured using sophisticated deposition or epitaxial growth techniques. However, some applications, such as carbon dot-based bulk nanocomposites for thermoelectric material [13], require a large number of CDs, preferably with some variation in size, shape, and surface features. The method described in this paper is a good and low-cost alternative for these applications.

Pyrolysis is a technique that can be used to convert waste into nanomaterials [10]. Through this process, waste tires are thermally decomposed into char, liquid, and syngas [14-16]. The pyrolytic char is a carbon-rich source composed of carbon black and inorganic substances used during tire manufacturing $[15,17,18]$, whose characteristics such as surface area, chemical surface composition, and pore development can be enhanced through activation processes $[19,20]$. During chemical activation, the carbon material is impregnated with a chemical activation agent (acid or alkali) before carbonization [19,21]. A variety of chemical agents have been used, including $\mathrm{KOH}$ as a high surface area promoter [19,21-23] and $\mathrm{H}_{2} \mathrm{SO}_{4}$ as a porosity controller [24].

The variety of existing carbon precursors and different synthesis methods has led to CDs with diverse properties and structures [25], making it necessary to study the effects associated with each variation. The effect of the synthesis method on the properties of the CDs has thus been investigated; Crista et al. [26] discovered differences in nitrogen doping between the different bottom-up strategies (hydrothermal, microwave assisted, and calcination). Similarly, the effects of varying synthesis process parameters such as reaction time [27] and the use of different precursors [28] have provided useful information for understanding $\mathrm{CD}$ properties. The modification of the carbon precursor by an activation process may contribute to the understanding of the properties of CDs.

To properly analyze $\mathrm{CDs}$, a purification process before characterization is needed, since byproducts (frequently formed during CDs synthesis) can modify CD fluorescence [29-31]. Essner et al. [30] demonstrated in this context that impurities should be removed in order to obtain reliable results on the properties of CDs. Furthermore, they examined a sample of over 550 reports and discovered that more than half of them used insufficient purification processes [30]. Some researchers investigated the required dialysis time to ensure CDs purification [29,30], whereas others used column chromatography for the same purpose [31]. However, these studies were performed on CDs synthesized by bottom-up pathways. An advantage of this synthesis approach is the production of CDs with a higher purity [32]. Therefore, the evaluation of the purification process of CDs synthesized by a chemical oxidation process (a top-down pathway) is needed.

In this study, CDs are synthesized from activated and non-activated pyrolytic carbon black from waste tire pyrolysis processes. The effects of the chemical composition of the precursor on the properties of CDs are investigated. Furthermore, the CDs dialysis purification process is examined to determine the time required for complete purification.

\section{Materials and Methods}

\subsection{Carbon Dots Synthesis}

Four different samples of carbon black were used as precursors for carbon dot synthesis using an oxidation method, followed by neutralization, ultrafiltration, and dialysis (Figure 1). 


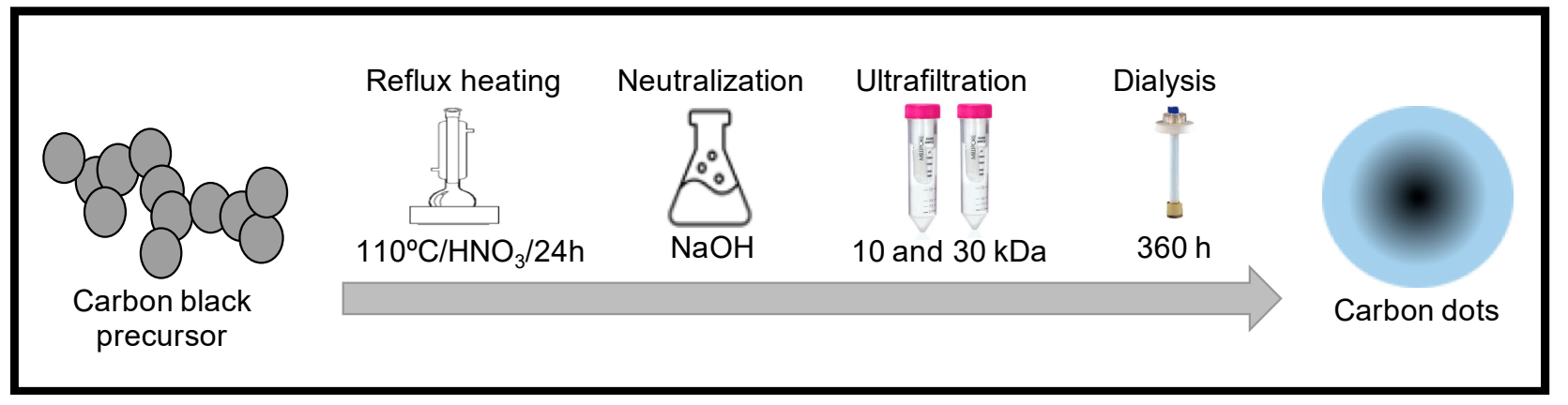

Figure 1. Chemical oxidation methodology followed for the synthesis of carbon dots from carbon black and activated carbon black as precursors.

Carbon black precursors were recovered by four different pyrolysis/activation processes: (1) pyrolysis, (2) $\mathrm{H}_{2} \mathrm{SO}_{4}$ activation and pyrolysis, (3) $\mathrm{KOH}$ activation and pyrolysis, and (4) $\mathrm{H}_{2} \mathrm{SO}_{4}$ activation, $\mathrm{KOH}$ activation, and pyrolysis. Carbon black was recovered from waste tire powder with a particle size of 75-125 $\mu \mathrm{m}$ obtained from LT Lehigh Technologies (Tucker, GA, USA). The detailed methodology is reported in [33]. In brief, when chemical activation (either $\mathrm{H}_{2} \mathrm{SO}_{4}$ or $\mathrm{KOH}$ ) was used, waste tire powder was impregnated at $80{ }^{\circ} \mathrm{C}$ with an activating agent/tire ratio of 4 before being filtered and dried. The activation temperature, weight ratio, and activation agents were chosen based on optimal values reported in the literature for improving the properties of carbon black $[19,21,33]$. The pyrolysis process was performed on a Lindberg Blue $\mathrm{M}$ tubular muffle (Thermo Scientific, Watertown, WI, USA) with a heating rate of $10^{\circ} \mathrm{C} / \mathrm{min}$ until reaching $950{ }^{\circ} \mathrm{C}$ with a nitrogen flow of $200 \mathrm{~mL} / \mathrm{min}$.

The recovered carbon black from each process was collected and used as a CD precursor with an adapted version of the chemical oxidation technique documented by Dong et al. [34]. Reflux heating of the carbon black precursors was performed at $110^{\circ} \mathrm{C}$ with $6 \mathrm{M} \mathrm{HNO}_{3}$ for $24 \mathrm{~h}$ with continuous stirring, then $\mathrm{NaOH}$ was used for neutralization. Finally, purification was performed by ultrafiltration and dialysis for $360 \mathrm{~h}$ using a SpectraPor $^{\circledR}$ Float-A-Lyzer ${ }^{\circledR}$ G2 of $10 \mathrm{~mL}$ with a membrane of 3.5-5 kDa. To ensure complete carbon dot purification, a Dionex ICS-1600 Ion Chromatography System was used after $48 \mathrm{~h}, 192 \mathrm{~h}, 240 \mathrm{~h}$, and $360 \mathrm{~h}$ of dialysis.

In the following sections of the manuscript, the synthesized carbon dots are identified as follows: carbon dots synthesized from carbon black as "Cd.CB", carbon dots from $\mathrm{H}_{2} \mathrm{SO}_{4}$ activated carbon black as " $\mathrm{Cd} . \mathrm{H}_{2} \mathrm{SO}_{4}$ ", carbon dots synthesized from $\mathrm{KOH}$-activated carbon black as " $\mathrm{Cd} . \mathrm{KOH}^{\prime}$, and carbon dots from $\mathrm{H}_{2} \mathrm{SO}_{4}$ and $\mathrm{KOH}$-activated carbon black as Cd. $\mathrm{H}_{2} \mathrm{SO}_{4}$, and $\mathrm{KOH} . s$ (4) (i.e., $\mathrm{H}_{2} \mathrm{SO}_{4}$ activation, followed by pyrolysis and $\mathrm{KOH}$ activation) as "CB. $\mathrm{H}_{2} \mathrm{SO}_{4}+\mathrm{KOH}^{\prime}$.

\subsection{Carbon Dots Characterization}

The optical properties of carbon dots were analyzed by UV-visible spectroscopy; this technique is useful to observe the region of absorption, which on carbon dots is typically in the UV region. On the other hand, some properties such as stability, biocompatibility, and photoluminescence are highly dependent on the presence of functional groups on their surface; therefore, characterization techniques such as FTIR, XPS, Raman, and $\zeta$ potential were performed. The analysis of the particle size, size distribution, and morphology was performed using images obtained by scanning electron microscopy (SEM) and transmission electron microscopy (TEM). Finally, a detailed analysis of the photoluminescence was performed, which is of great interest since many of its applications are based on these properties.

Optical properties of diluted carbon dot suspension were analyzed with PerkinElmer $\mathrm{UV} /$ Vis Lambda 365 equipment. The absorbance measurements were performed in the 200-800 nm wavelength range. A Frontier FT-IR Spectrometer (PerkinElmer, Waltham, MA, 
USA) with the Universal ATR sampling accessory was used to analyze functional surface groups. The measurements were performed in the transmission range of $400 \mathrm{~cm}^{-1}$ to $4000 \mathrm{~cm}^{-1}$ with 64 scans. XPS analysis was performed with a Thermo Scientific ESCALAB 250Xi spectrometer (East Grinstead, West Sussex, UK) equipped with 8 Channeltron detectors. $\mathrm{AlK}_{\alpha}$ radiation $(1486.68 \mathrm{eV})$ was used as a source of ionizing radiation. The survey spectra were measured at the $1100 \mathrm{eV}$ pass energy with a resolution of $1 \mathrm{eV}, 100 \mathrm{~ms}$, and $150 \mathrm{eV}$ pass energy. High-resolution spectra were collected at $0.1 \mathrm{eV}, 100 \mathrm{~ms}$, and $20 \mathrm{eV}$ pass energy. The analysis was performed under ultrahigh vacuum $\left(10^{-10} \mathrm{Torr}\right)$, and signals were assigned using the NIST database.

Carbon structure was studied by Raman spectroscopy using LabRAM HR Evolution (Horiba Scientific, Jobin Yvon, Longjumeau, France) equipment with a $532 \mathrm{~nm}$ laser as an excitation source. Raman scattered light was detected by a CCD camera operating at $220 \mathrm{~K}$. An Olympus microscope SLMPN 50×/0.35 NA was used to focus the laser on the sample. Raman signals were acquired at $25 \%, 50 \%$, and $100 \%$ of the beam intensity. Band intensity, band position, and area were obtained using a Lorentz curve fitting procedure on the normalized Raman spectra.

To analyze the surface charge of the carbon dots, the $\zeta$ potential was measured by Phase-analysis light scattering (PALS) with a NanoBrook 90Plus PALS Brookhaven instrument performing 10 measurements per sample and using the Smoluchowski equation to convert the electrophoretic mobility of the particles obtained by the instrument into the $\zeta$ potential. Carbon dots nanoparticles were observed using Transmission electron microscopy (TEM). Bright-field (BF) images were acquired in a transmission electron microscope Hitachi HT7700 operated at $100 \mathrm{kV}$. Carbon dots samples were dispersed in distilled water with the aid of an ultrasound bath. A drop of the dispersed solution was placed on a 300-mesh copper grid covered with a lacey carbon film. With a diffraction aperture of $500 \mathrm{~nm}$ in diameter, selected area electron diffraction (SAED) patterns were obtained. The fluorescence was measured with a Horiba FluoroMax-4 Spectrofluorometer with an excitation range of $340 \mathrm{~nm}$ to $543 \mathrm{~nm}$ and an emission range of $370 \mathrm{~nm}$ to $750 \mathrm{~nm}$.

\section{Results and Discussion}

\subsection{Carbon Dot Purification}

The formation of undesirable byproducts, unreacted precursors, or impurities is almost inevitable during the synthesis of carbon dots. Thus, synthesized carbon dots were purified through dialysis before their analysis. Figure 2 shows the ion chromatography results from carbon dots after $48 \mathrm{~h}, 192 \mathrm{~h}, 240 \mathrm{~h}$, and $360 \mathrm{~h}$ of dialysis. The presence of chloride, nitrate, and sulfate was observed, though these were not detected after $360 \mathrm{~h}$ of dialysis. The presence of nitrate salts is caused by the neutralization of $\mathrm{HNO}_{3}$ with $\mathrm{NaOH}$. The presence of sulfates may not be due to $\mathrm{H}_{2} \mathrm{SO}_{4}$ activation of the precursor because CDs from nonactivated carbon black had a low concentration of sulfates. Sulfates may be formed during chemical oxidation with the precursor, which reported a sulfur content between $1.4 \%$ and $4.5 \%$ [33]. The low concentration of chloride might be due to the dilution preparations of the required chemical agents and from the double-distilled water used during dialysis.

Chen et al. [29] reported that it takes around $120 \mathrm{~h}$ to completely purify CDs synthesized from citric acid, which is much longer than the regular dialysis time used in $C D$ studies, suggesting also that the purification is frequently insufficient [29]. Ion chromatography revealed that it took up to $360 \mathrm{~h}$ to purify the carbon dots in our study. Purification times obtained here are longer than those reported for carbon dots synthesized using bottom-up synthesis methods by Chen et al. [29], who reported $\sim 120 \mathrm{~h}$ to completely purify CDs. Synthesis methods belonging to the top-down approach lead to a relatively high yield of products; however, the purity of products is typically higher when the bottom-up synthesis approach is performed [32]. Moreover, if carbon dots are prepared from biomass or waste materials instead of pure chemicals, numerous impurities can be formed. In this manner, the synthesis of carbon dots from biomass or waste precursors is still challenging 
due to non-standard synthesis methods and the presence of impurities, which may lead to a longer time for a proper purification.

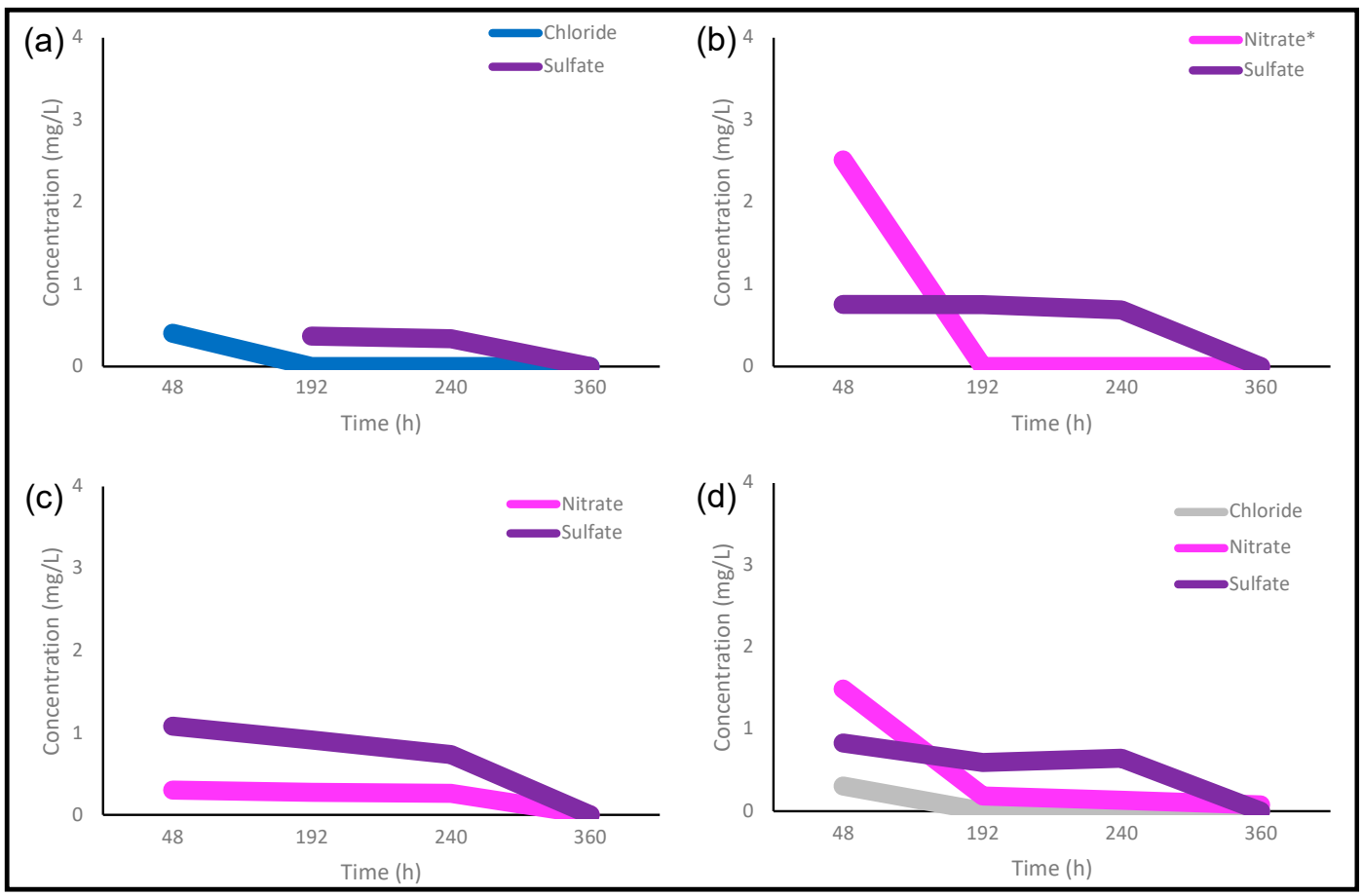

Figure 2. Ion chromatogram of (a) Cd.CB, (b) $\mathrm{Cd}_{2} \mathrm{H}_{2} \mathrm{SO}_{4}$, (c) $\mathrm{Cd} . \mathrm{KOH}$ and (d) $\mathrm{Cd} . \mathrm{H}_{2} \mathrm{SO}_{4}+\mathrm{KOH}$ at different dialysis times. Note: * Nitrate concentration in panel b was divided by four for comparison purposes.

\subsection{Carbon Dot Characterization}

Pyrolytic carbon black recovered by waste tire pyrolysis was used as the starting material. Four different processes were performed to modify the characteristics of the recovered carbon black: (1) pyrolysis, (2) $\mathrm{H}_{2} \mathrm{SO}_{4}$ activation and pyrolysis, (3) $\mathrm{KOH}$ activation and pyrolysis, and (4) $\mathrm{H}_{2} \mathrm{SO}_{4}$ activation, $\mathrm{KOH}$ activation, and pyrolysis. The complete characterization of the carbon black recovered from each process is presented in our previous research [33]. The differences presented in their elemental composition, surface area, and Raman spectra $\left(\mathrm{I}_{\mathrm{D}} / \mathrm{I}_{\mathrm{G}}\right.$ ratio), obtained by an Organic Elemental CHNS-O Analyzer Flash 2000 (Thermo Scientific ${ }^{\text {TM }}$, Waltham, MA, USA), an Autosorb IQ TPX Quantachrome gas adsorption analyzer (Boynton Beach, FL, USA) using the BET method, and a LabRAM HR Evolution (Horiba, Jobin Yvon, Longjumeau, France), respectively, are presented in Table 1. The chemical activations $\left(\mathrm{H}_{2} \mathrm{SO}_{4}, \mathrm{KOH}\right.$, and $\left.\mathrm{H}_{2} \mathrm{SO}_{4}+\mathrm{KOH}\right)$ caused an increase in the oxygen content and surface area compared to the nonactivated carbon black.

Table 1. Characterization of recovered carbon black used as precursor.

\begin{tabular}{ccccc}
\hline & Carbon Black & $\begin{array}{c}\mathbf{H}_{\mathbf{2}} \mathbf{S O}_{4} \text {-Activated } \\
\text { Carbon Black }\end{array}$ & $\begin{array}{c}\text { KOH-Activated } \\
\text { Carbon Black }\end{array}$ & $\begin{array}{c}\mathbf{H}_{\mathbf{2}} \mathrm{SO}_{4}+\mathrm{KOH}_{\text {-Activated }} \\
\text { Carbon Black }\end{array}$ \\
\hline Nitrogen (\%) & 0.90 & 0.86 & 0.97 & 1.02 \\
Carbon (\%) & 79.46 & 86.90 & 70.38 & 60.75 \\
Hydrogen (\%) & 0.30 & 0.41 & 0.44 & 0.75 \\
Sulfur (\%) & 3.09 & 1.36 & 3.04 & 4.45 \\
Oxygen (\%) & 0.70 & 0.97 & 8.79 & 16.06 \\
Surface area (m $\left.{ }^{2} / \mathrm{g}\right)$ & 57 & 302 & 197 & 82 \\
$\mathrm{I}_{\mathrm{D}} / \mathrm{I}_{\mathrm{G}}$ & 0.96 & 1.01 & 0.94 & 0.93 \\
\hline
\end{tabular}

Note: Adapted from Tables 2 and 3 from Gonzalez-Gonzalez et al. [33]. 
To analyze the optical properties of carbon dots, UV-visible absorption was measured. Figure 3 shows that carbon dot samples did not present strong differences in the spectra. All samples showed broad adsorption that extended to the visible region, with peaks associated with the carbonic core center at $255 \mathrm{~nm}$ and $272 \mathrm{~nm}[6,35]$, indicating extended conjugation in the carbon dot structure $[6,36]$. The adsorption peak at $255 \mathrm{~nm}$ is specifically ascribed to the $\pi-\pi^{*}$ transition of carbon-carbon double bond $(C=C)$ and the peak at $272 \mathrm{~nm}$ to the $\pi-\pi^{*}$ transition of carbon-nitrogen double bond $(C=N)[37,38]$. On the other hand, the absorption peak at $401 \mathrm{~nm}$ was related to the surface of the carbon dots [6,35], specifically to the $n-\pi^{*}$ transition of $C=N$ [39]. An additional peak around $340 \mathrm{~nm}$ was mainly observed in Cd.CB, which was attributed to $n-\pi^{*}$ transition bands on carbon dots demonstrating the presence of doping elements [40].

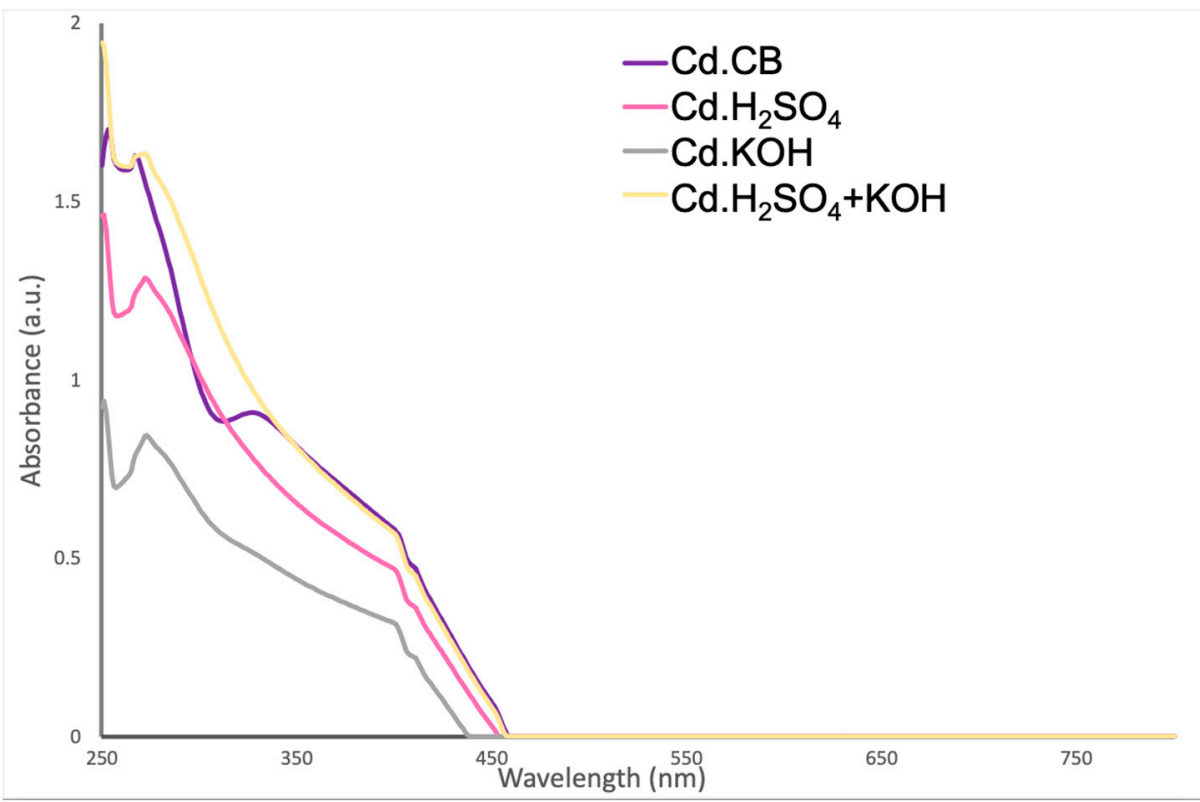

Figure 3. UV-visible spectra of carbon dots.

Functional groups in synthesized carbon dots were analyzed by FTIR, XPS, Raman, and $\zeta$ potential. In the FTIR spectra presented in Figure 4, a strong broad peak approximately at $3361 \mathrm{~cm}^{-1}$ associated with $\mathrm{O}-\mathrm{H}$ stretching vibration [41-47] is observed, suggesting the existence of carboxyl and hydroxyl groups resulting in the hydrophilic behavior of the carbon dots samples. The peak at $2100 \mathrm{~cm}^{-1}$ is associated with the bending vibration of $\mathrm{C}=\mathrm{C}$ from aromatic structure [48], while the peak at $1377 \mathrm{~cm}^{-1}$ is attributed to the stretching vibration of $-\mathrm{COOH}[43]$. The presence of nitro $\left(\mathrm{NO}_{2}\right)$ groups was confirmed with two peaks approximately at $1639 \mathrm{~cm}^{-1}$ and $600 \mathrm{~cm}^{-1}$, which are assigned to the symmetric stretching and asymmetric stretching of nitro groups, respectively [49]. FTIR results suggest the presence of carboxyl $(\mathrm{COOH})$, hydroxyl $(\mathrm{OH})$, and nitro $\left(\mathrm{NO}_{2}\right)$ functional groups on the carbon surface introduced during chemical oxidation with $\mathrm{HNO}_{3}[50,51]$. According to Datsyuk et al. [50], $\mathrm{HNO}_{3}$ - treated carbon material had the highest increase in oxygen-containing groups when compared to other oxidants, which is consistent with other studies [52]. Nitrogen can be introduced through a reaction similar to benzene nitration, producing highly reactive nitronium ion [53,54]. The nitrogen on the surface of CDs may be in the form of nitro groups, as observed in FTIR spectra and literature [51,53-55].

XPS was measured to analyze the different types of functional groups on the carbon dots surface. A similar chemical structure was observed in the different carbon dots samples (Figure 5). Four predominant peaks were found: C1s, O1s, N1s, and S2p. 


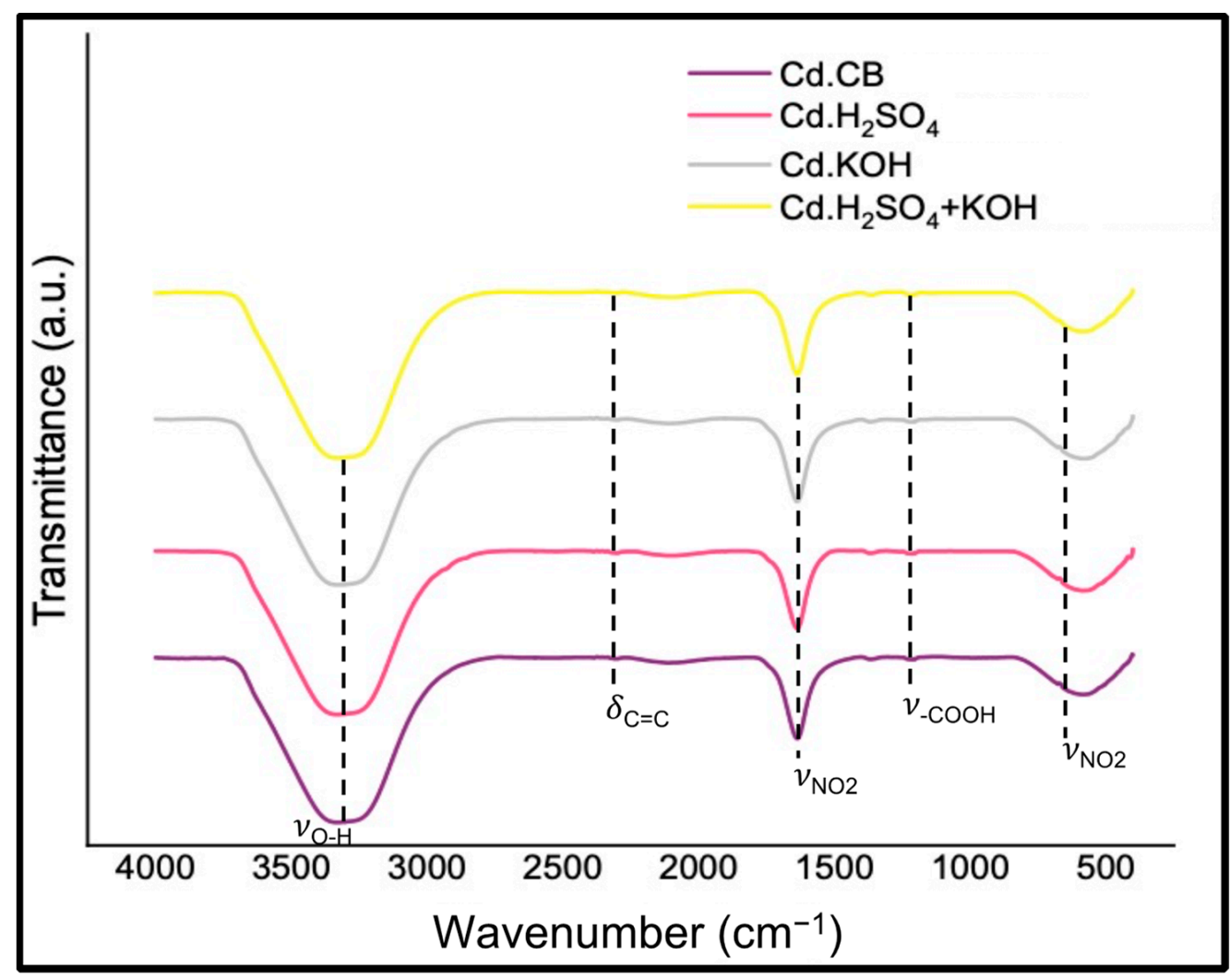

Figure 4. FTIR spectra of carbon dots.

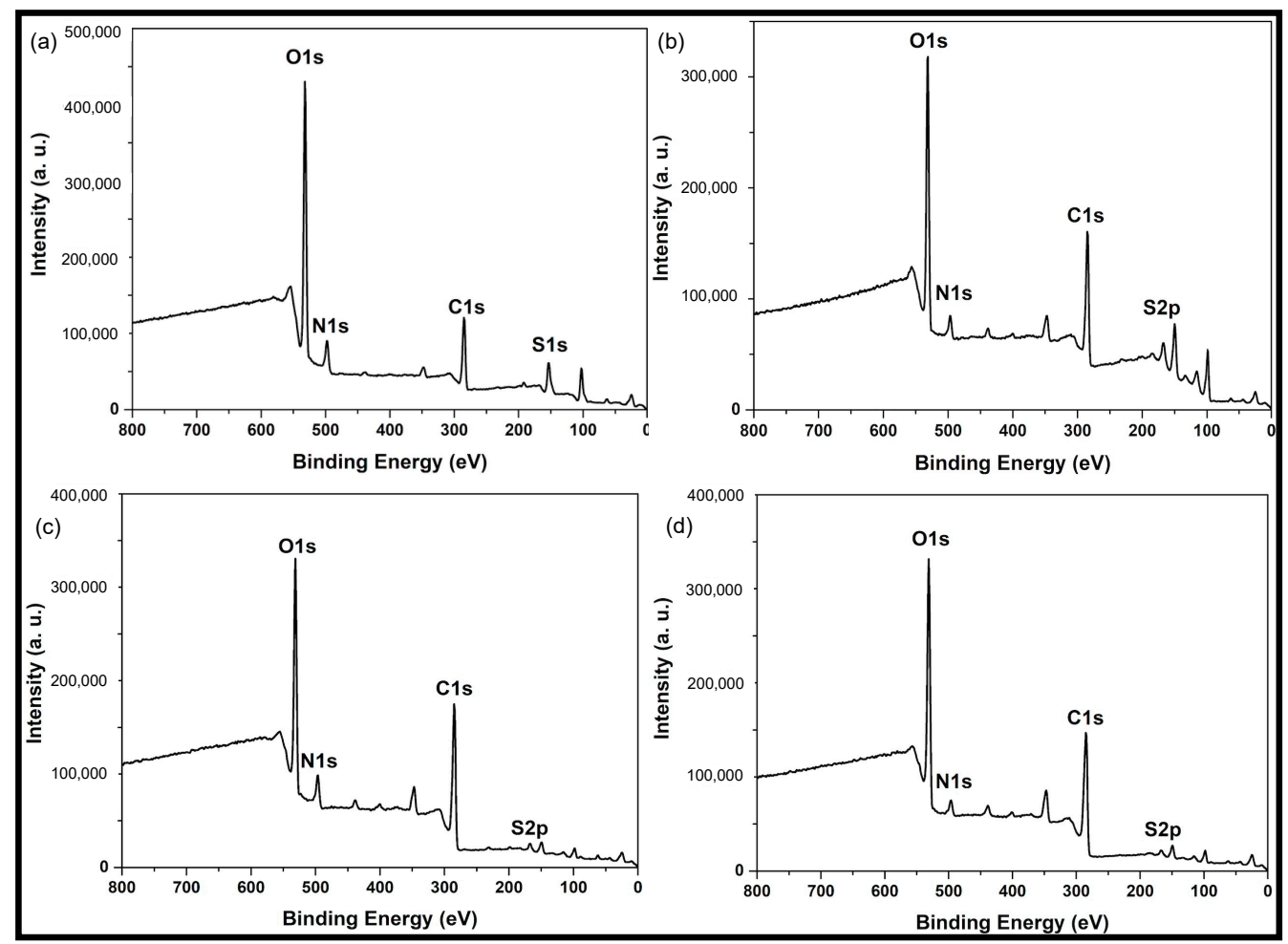

Figure 5. XPS survey spectrum of (a) Cd.CB, (b) $\mathrm{Cd}_{2} \mathrm{H}_{2} \mathrm{SO}_{4}$, (c) $\mathrm{Cd} \cdot \mathrm{KOH}$, and (d) $\mathrm{Cd}_{2} \mathrm{H}_{2} \mathrm{SO}_{4}+\mathrm{KOH}$.

$\mathrm{C} 1 \mathrm{~s}, \mathrm{~N} 1 \mathrm{~s}$, and S2p peaks were deconvoluted to identify their components (Figure 6). C1s from samples Cd.CB and Cd.KOH was deconvoluted into $\mathrm{C} \mathrm{sp}^{2}$ (at $\sim 284.29 \mathrm{eV}$ ), $\mathrm{C} \operatorname{sp}^{3}$ (at $\left.\sim 284.73 \mathrm{eV}\right), \mathrm{C}-\mathrm{N} / \mathrm{C}-\mathrm{S}($ at $\sim 285.96 \mathrm{eV}), \mathrm{C}-\mathrm{OH}($ at $\sim 286.54 \mathrm{eV})$, and $\mathrm{O}-\mathrm{C}=\mathrm{O}$ (at 
$\sim 288.14 \mathrm{eV}$ ). Two additional components were found in $\mathrm{Cd}_{2} \mathrm{H}_{2} \mathrm{SO}_{4}$ : at $287.83 \mathrm{eV}$ attributed to $\mathrm{C}=\mathrm{O}$ and $\mathrm{C}-\mathrm{O}-\mathrm{C}$ at $287.10 \mathrm{eV}$. Similarly, in sample $\mathrm{Cd}_{2} \mathrm{H}_{2} \mathrm{SO}_{4}+\mathrm{KOH}$ was observed additional peaks at $287.67 \mathrm{eV}$ and $290.61 \mathrm{eV}$ attributed to $\mathrm{C}=\mathrm{O}$ and $\mathrm{CO}_{3}{ }^{2-}$, respectively, indicating an even higher oxidation degree in this sample. The atomic percentages of C1s, N1s, and O1s varied as can be seen in Table 2. The sum of the atomic percentage of the oxygen-containing groups in $\mathrm{C} 1 \mathrm{~s}$ on the carbon dots from activated precursors was in the range of $26.23-31.96 \%$, while in Cd.CB the atomic percentage was $20.21 \%$. The increase in this value suggests a higher oxidation degree in carbon dots prepared from activated precursors. This is also supported by a decrease in hydroxyl $(\mathrm{C}-\mathrm{OH})$ and an increase in $\mathrm{O}-\mathrm{C}-\mathrm{O}$ because hydroxyl groups are formed at lower oxidation levels and then converted into epoxy groups as the oxidation level increases [56]. On the other hand, the atomic percentage of N1s and S2p increased on carbon dots from activated precursors, implying that surface functional groups were better attached during chemical oxidation when the precursor was previously activated. The XPS results are in agreement with the FTIR results, suggesting the presence of nitrogen-, oxygen-, and sulfur-containing groups on the carbon dot surface.

Table 2. The atomic percentage of functional groups deconvoluted in C1s, N1s, and S2p from XPS spectrum of carbon dots samples.

\begin{tabular}{|c|c|c|c|c|}
\hline \multirow{2}{*}{ Components } & \multicolumn{4}{|c|}{ Atomic \% } \\
\hline & Cd.CB & $\mathrm{Cd} . \mathrm{H}_{2} \mathrm{SO}_{4}$ & Cd.KOH & $\mathrm{Cd} . \mathrm{H}_{2} \mathrm{SO}_{4}+\mathrm{KOH}$ \\
\hline C 1s & 39.31 & 52.23 & 56.38 & 58.45 \\
\hline $\mathrm{Csp} \mathrm{sp}^{2}$ & 34.47 & 35.47 & 37.69 & 33.56 \\
\hline $\mathrm{Csp}$ & 41.18 & 33.05 & 24.81 & 25.66 \\
\hline $\mathrm{C}-\mathrm{N} / \mathrm{C}-\mathrm{S}$ & 4.25 & 5.26 & 10.9 & 8.82 \\
\hline Hydroxyl $(\mathrm{C}-\mathrm{OH})$ & 5.99 & 4.70 & 4.04 & 3.01 \\
\hline Carboxyl $(\mathrm{O}-\mathrm{C}=\mathrm{O})$ & 14.22 & 10.79 & 22.56 & 19.67 \\
\hline Carbonyl $(\mathrm{C}=\mathrm{O})$ & - & 9.82 & - & 6.89 \\
\hline Ether $(\mathrm{C}-\mathrm{O}-\mathrm{C})$ & - & 0.92 & - & - \\
\hline Carbonate $\left(\mathrm{CO}_{3}{ }^{2-}\right)$ & - & - & - & 2.39 \\
\hline N1s & 0.82 & 1.78 & 1.8 & 2.28 \\
\hline Imide $(\mathrm{O}=\mathrm{C}-\mathrm{N}-\mathrm{C}=\mathrm{O})$ & 65.04 & 70.7 & 21.54 & 65.51 \\
\hline Nitro $\left(\mathrm{NO}_{2}\right)$ & 34.96 & 29.3 & 31.58 & 34.49 \\
\hline $\mathrm{N}-(\mathrm{C}=\mathrm{O})-\mathrm{N}$ & - & - & 35.88 & - \\
\hline $\mathrm{S} 2 \mathrm{p}$ & 0.8 & 4.78 & 1.73 & 1.69 \\
\hline Sulfoxides $(\mathrm{S}=\mathrm{O})$ & 69.02 & 28.18 & - & - \\
\hline Sulfonic acid $\left(\mathrm{SO}_{3} \mathrm{H}\right)$ & 30.98 & 71.82 & 74.64 & 77.97 \\
\hline Sulfides $(\mathrm{C}-\mathrm{S}-\mathrm{C})$ & - & - & 25.36 & 22.03 \\
\hline
\end{tabular}

Results from Raman spectroscopy are presented in Table 3 and Figure 7. The D band at approximately $1350 \mathrm{~cm}^{-1}$ is attributed to the functional groups on the carbon dots surface and indicates hydrocarbon or aliphatic moieties connected to the graphitic structure [11,57]. The $\mathrm{G}$ band, which appears around $1580 \mathrm{~cm}^{-1}$, corresponds to in-place vibrations and shows the presence of small graphitic planes or microcrystallites. The Raman spectra (Figure 7) obtained from all of the carbon dots samples show a high degree of surface functionalization, which is consistent with the findings of Wu et al. [58], who reported that defects on graphene quantum dots during chemical passivation cause an increase in the $\mathrm{D}$ band.

Carbon dots from activated precursors, except for $\mathrm{Cd} . \mathrm{H}_{2} \mathrm{SO}_{4}+\mathrm{KOH}$ with an $\mathrm{I}_{\mathrm{D}} / \mathrm{I}_{\mathrm{G}}$ of 0.99, presented an increase in their $\mathrm{I}_{\mathrm{D}} / \mathrm{I}_{\mathrm{G}}\left(\mathrm{Cd} \cdot \mathrm{H}_{2} \mathrm{SO}_{4}\right.$ with an $\mathrm{I}_{\mathrm{D}} / \mathrm{I}_{\mathrm{G}}$ of 1.30 and $\mathrm{Cd} . \mathrm{KOH}$ with an $\mathrm{I}_{\mathrm{D}} / \mathrm{I}_{\mathrm{G}}$ of 1.38 ) compared to the $\mathrm{I}_{\mathrm{D}} / \mathrm{I}_{\mathrm{G}}$ of 1.13 obtained from Cd.CB. This suggests a higher introduction of functional groups in the activated precursors. In addition, all carbon dot samples exhibited an increase in $\mathrm{I}_{\mathrm{D}} / \mathrm{I}_{\mathrm{G}}$ compared with their respective precursor, showing the effect of the increasing $\mathrm{D}$ band due to the oxygen-containing groups on the surface of carbon dots. 

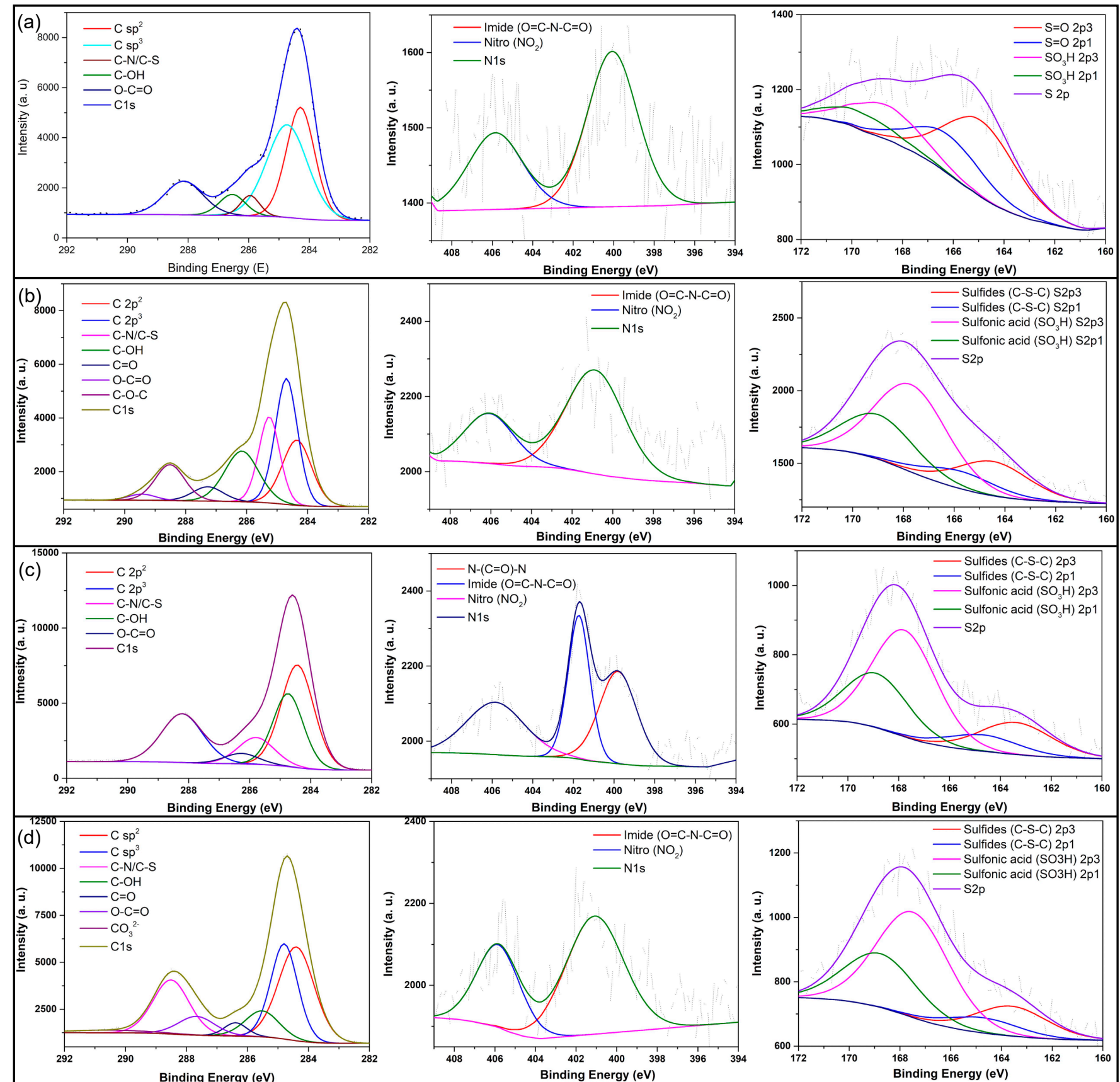

Figure 6. High-resolution XPS spectra of C1s, N1s, and S2p of (a) Cd.CB, (b) Cd. $\mathrm{H}_{2} \mathrm{SO}_{4},(\mathbf{c}) \mathrm{Cd} . \mathrm{KOH}$, and (d) $\mathrm{Cd} \cdot \mathrm{H}_{2} \mathrm{SO}_{4}+\mathrm{KOH}$.

The $\zeta$ potential values presented in Table 4 were measured to obtain the surface charge of carbon dots and therefore the presence of functional groups. The low absolute value of $\zeta$ potential (less than $25 \mathrm{mV}$ ) in all carbon dot samples indicates their proclivity to aggregate due to their low physical stability. Cd.CB demonstrated superior stability with the highest absolute value. It should be noted that $\zeta$ potential was measured after months of carbon dot synthesis, which likely affected the stability of the carbon dots. However, it is common to find in literature carbon dots with a low absolute $\zeta$ potential value, with some successful applications [59-61] reporting good stability regardless of the low absolute value. Among these, Radhakrishan et al. [60] evaluated the $\zeta$ potential before and after a passivation process, finding a decrease from $-18.6 \mathrm{mV}$ to -4.06 when glycine was used as the surface passivizing agent. Despite the low absolute value, over a month, carbon dots exhibited a 
homogeneous phase with no precipitate formation, and the carbon dots were successfully validated as an effective fluorescent sensor for the detection of metallic ions from aqueous solutions [60].

Table 3. Fitting parameters from Raman spectra of carbon dots samples.

\begin{tabular}{ccccc}
\hline & Cd.CB & Cd. $\mathbf{H}_{\mathbf{2}} \mathbf{S O}_{\mathbf{4}}$ & $\mathbf{C d . K O H}$ & $\mathbf{C d . H}_{\mathbf{2}} \mathbf{S O}_{\mathbf{4}}+\mathbf{K O H}$ \\
\hline $\mathrm{I}_{\mathrm{D}} / \mathrm{I}_{\mathrm{G}}$ & 1.13 & 1.30 & 1.38 & 0.99 \\
$\mathrm{D}$ band position $\left(\mathrm{cm}^{-1}\right)$ & 1355 & 1355 & 1357 & 1341 \\
$\mathrm{D}$ band area & 153 & 219 & 0.79 & 156 \\
$\mathrm{D}$ band height & 0.92 & 0.88 & 98 & 0.93 \\
$\mathrm{D}$ band FWHM & 106 & 158 & 1602 & 107 \\
$\mathrm{G}$ band position $\left(\mathrm{cm}^{-1}\right)$ & 1596 & 1588 & 44 & 1591 \\
$\mathrm{G}$ band area & 59 & 88 & 0.57 & 85 \\
$\mathrm{G}$ band height & 0.81 & 0.68 & 49 & 0.93 \\
$\mathrm{G}$ band FWHM & 106 & 82 & & 58 \\
\hline
\end{tabular}

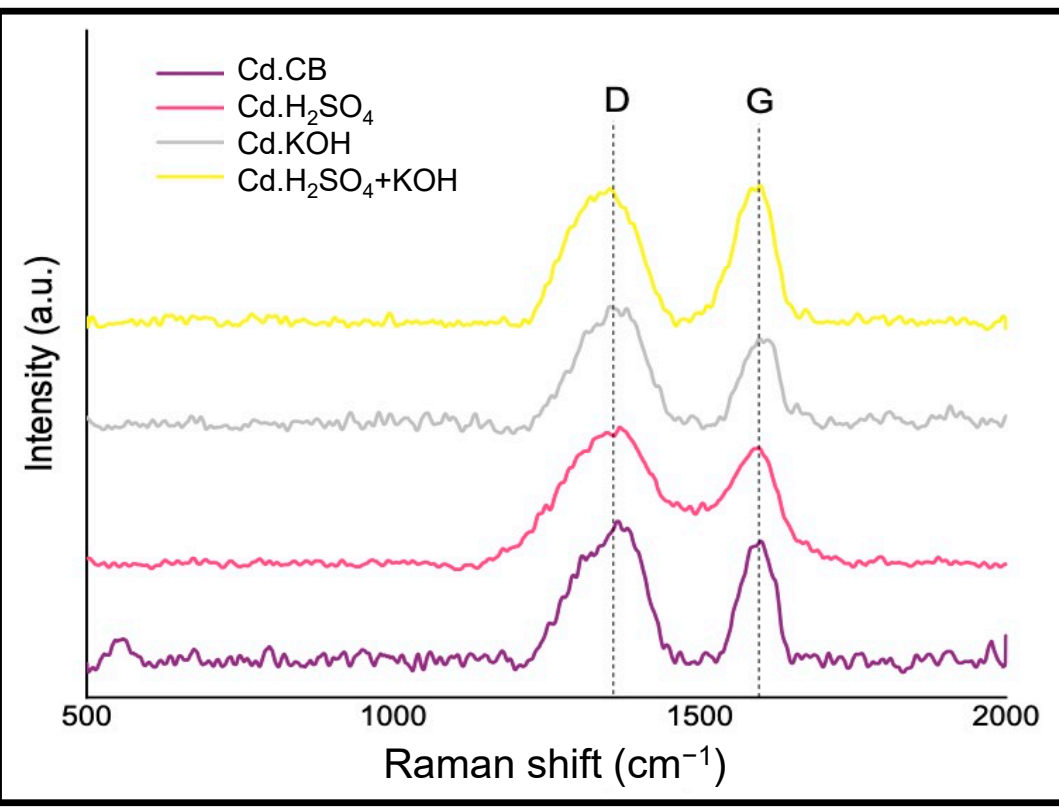

Figure 7. Raman spectra of carbon dots.

Table 4. $\zeta$ Potential results from carbon dots samples.

\begin{tabular}{ccccc}
\hline Sample & \multicolumn{4}{c}{ 乙 Potential $(\mathbf{m V})$} \\
\hline $\mathrm{Cd} . \mathrm{CB}$ & -11.61 & \pm & 1.59 & \\
$\mathrm{Cd} . \mathrm{H}_{2} \mathrm{SO}_{4}$ & -5.20 & \pm & 2.60 & $\mathrm{~A}$ \\
$\mathrm{Cd} . \mathrm{KOH}$ & -4.22 & \pm & 2.17 & $\mathrm{~A}$ \\
$\mathrm{Cd} . \mathrm{H}_{2} \mathrm{SO}_{4}+\mathrm{KOH}$ & -1.28 & \pm & 1.16 & \\
\hline
\end{tabular}

Note: Mean values with the same letter are not statistically different (Tukey's test, $p$-value $>0.05$ ).

The negative charge observed in our study indicates a dense electron cloud concentrating on the carbon dots [62], attributed to carboxyl, hydroxyl, or carbonyl groups in the nanoparticle surface [63]. Carbon dots from activated precursors $\left(\mathrm{Cd} . \mathrm{H}_{2} \mathrm{SO}_{4}, \mathrm{Cd} . \mathrm{KOH}\right.$, and $\mathrm{Cd} . \mathrm{H}_{2} \mathrm{SO}_{4}+\mathrm{KOH}$ ) showed a less negative $\zeta$ potential from $-11.61 \mathrm{mV}$ to $-5.20 \mathrm{mV}$, $-4.22 \mathrm{mV}$ and $-1.28 \mathrm{mV}$, respectively, compared with Cd.CB. The slight increase in the band associated with $\mathrm{C}=\mathrm{O}$ observed in $\mathrm{UV}$-visible spectra suggests that the increase in negative surface charge on Cd.CB is due to a higher content of electron-withdrawing oxygen-containing groups on its surface. 
In addition, a Shapiro-Wilk normality test on the residuals ( $p$-value $=0.4791$ ) and Levene's test ( $p$-value $=0.1390$ ) for homogeneity of variance were performed to verify the assumptions of normal distribution and homogeneity of variance, which were fulfilled by the data. The significance of differences in $\zeta$ potential values between carbon dots samples was then determined with an ANOVA test. Because all of the process parameters were under control, the differences observed were solely due to the precursor's activation. A significance value $(p$-value $<0.05)$ for the interaction of the two factors (presence of $\mathrm{H}_{2} \mathrm{SO}_{4}$ activation and presence of $\mathrm{KOH}$ activation in the precursor) was obtained; therefore, a Tukey's test was performed to identify these differences. Tukey's tests showed that $\zeta$ potential of $\mathrm{Cd}_{2} \mathrm{H}_{2} \mathrm{SO}_{4}$ and $\mathrm{Cd} . \mathrm{KOH}$ are not statistically different, while $\mathrm{Cd} . \mathrm{CB}$ and $\mathrm{Cd} . \mathrm{H}_{2} \mathrm{SO}_{4}+\mathrm{KOH}$ are statistically different from each other and compared with the other carbon dots samples. These findings support differences in the surface negative charge of carbon dots associated with functional groups: carbon dots synthesized from nonactivated carbon black had better suspension stability, whereas carbon dots synthesized from activated precursors had a lower negative $\zeta$ potential.

To obtain images of the carbon dots on the nanometer scale, transmission electron microscopy (TEM) was performed. Figure 8 shows bright-field transmission electron microscopy (BF-TEM) micrographs of CDs samples. Overall, spherical-shaped nanoparticles with sizes in the range of 10-50 nm were observed. TEM images of CDs with particle sizes bigger than $10 \mathrm{~nm}$ have been also reported in the literature $[64,65]$, which have been mainly attributed to agglomeration. Due to the small size of carbon dots, they tend to agglomerate in the solid state. Agglomeration of the nanoparticles was observed in all samples, which was expected given the $\zeta$ potential obtained in the range of -1.28 to $-11.61 \mathrm{mV}$. In addition, aggregation may be also caused by the drying process during sample preparation for TEM analysis [59]. The SAED revealed a diffuse ring diffraction pattern, which is indicative of short-range order or an amorphous microstructure, implying that the samples are mostly amorphous. However, in $\mathrm{Cd}_{\mathrm{H}} \mathrm{H}_{2} \mathrm{SO}_{4}$ and $\mathrm{Cd} . \mathrm{H}_{2} \mathrm{SO}_{4}+\mathrm{KOH}$ (Figure $8 \mathrm{i}, \mathrm{j}$ ) some crystalline areas with interlayer space of $0.34 \mathrm{~nm}$ were observed. A larger interlayer space than that for crystalline graphite $(0.335 \mathrm{~nm})$ and no stacking order indicates a turbostratic graphite structure [66]. This observation suggested that the $\mathrm{H}_{2} \mathrm{SO}_{4}$-activated precursor produces carbon dots with some degree of order in the carbon structure. The $\mathrm{KOH}$-activated precursor, on the other hand, had no crystalline areas, indicating that the amorphous carbon had not graphitized. In summary, the acid activation method produced more graphitized domains than the basic activation method [67], but all of the samples were a random mix of crystalline, amorphous, quasi 2D, quasi 0D, quasi 1Dm, and arbitrary shaped C islands with surface functionalization.

In addition to the spherical carbon dots nanoparticles, other irregular shape carbon particles were observed in TEM micrographs (Figure 9). Sample Cd.CB showed the presence of graphite-like particles, while graphene platelets were observed in samples prepared from Cd. $\mathrm{H}_{2} \mathrm{SO}_{4}$-activated precursors. Different diffracting crystalline planes were visible in the inset SAED patterns in Figure 9a,b, indicating an ordered microstructure. The presence of graphite in the Cd.CB may be due to unreacted precursor residues that could be converted into carbon dots with a longer reaction time. Other reports have found particles that are significantly smaller than the starting material but larger than carbon dots, despite filtration and dialysis [27]. The presence of graphene platelets in the samples from the activated precursors may be attributed to the occurrence of enhanced oxidation. Oxidation is widely used during the exfoliation process of graphite in the synthesis of graphene platelets, forming graphite oxide as intermediate products [68]. The oxygen-containing functional groups in graphite oxide have been shown to induce local strain and facilitate graphene monolayer exfoliation $[56,68,69]$. The formation of epoxide groups at higher oxidation levels influences the increase in interlayer spacing and exfoliation into graphene oxide [56]; these functional groups were visible in XPS spectra of $\mathrm{H}_{2} \mathrm{SO}_{4}$-activated precursors. Therefore, we suggest that the higher surface area and the presence of reactive functional groups 
on the activated precursors may enhance the oxidation process facilitating the formation of graphene.

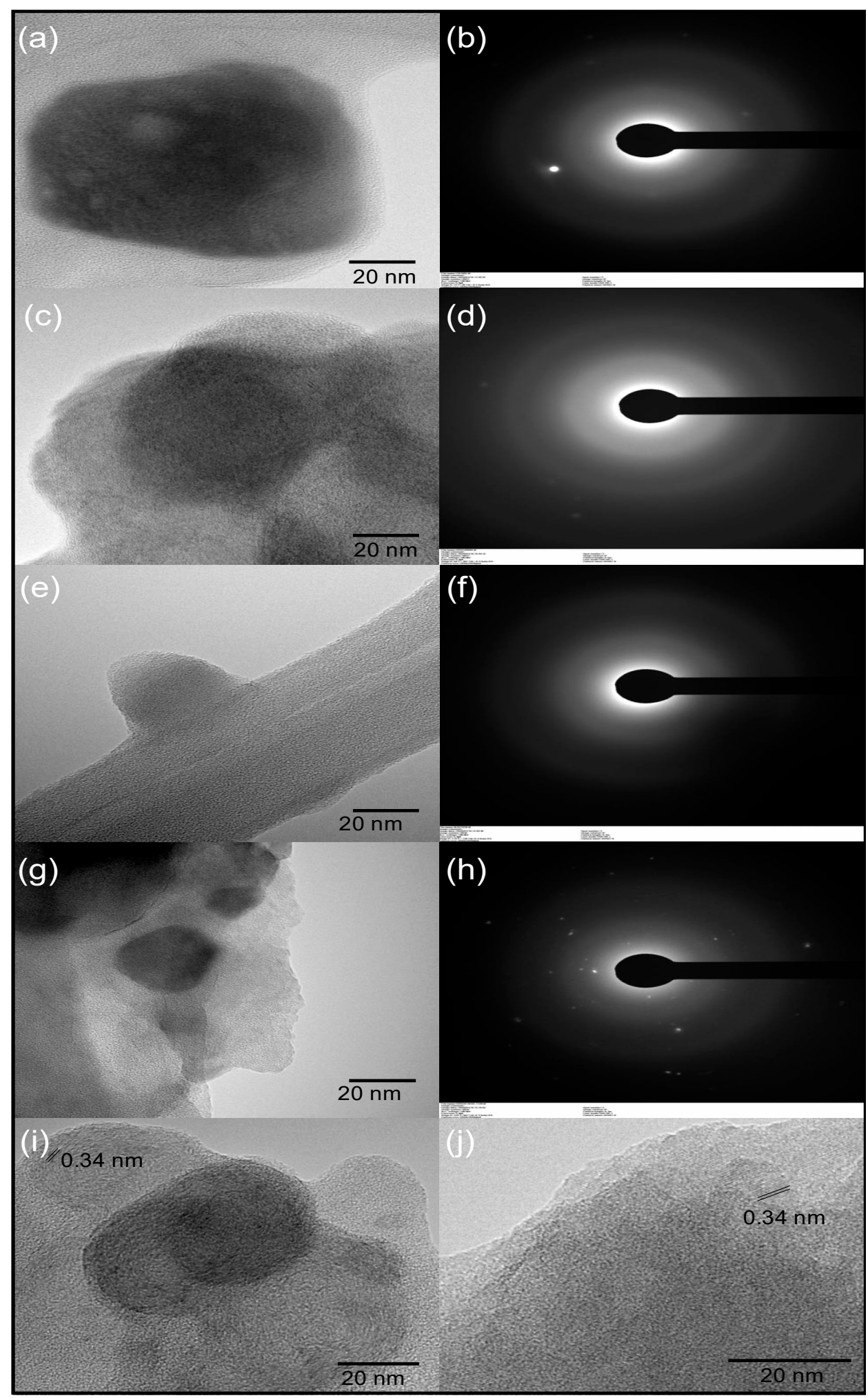

Figure 8. TEM images of (a) Cd.CB, (c) $\mathrm{Cd}_{2} \mathrm{H}_{2} \mathrm{SO}_{4}$, (e) $\mathrm{Cd} . \mathrm{KOH}$, and (g) $\mathrm{Cd}_{2} \mathrm{H}_{2} \mathrm{SO}_{4}$ $+\mathrm{KOH}$. Selected area electron diffraction (SAED) pattern of (b) Cd.CB, (d) Cd. $\mathrm{H}_{2} \mathrm{SO}_{4}$, (f) $\mathrm{Cd} . \mathrm{KOH}$ and (h) $\mathrm{Cd} \cdot \mathrm{H}_{2} \mathrm{SO}_{4}+\mathrm{KOH}$. TEM images showing lattice fringes of (i) $\mathrm{Cd}_{2} \mathrm{H}_{2} \mathrm{SO}_{4}$ and (j) $\mathrm{Cd} \cdot \mathrm{H}_{2} \mathrm{SO}_{4}+\mathrm{KOH}$. 


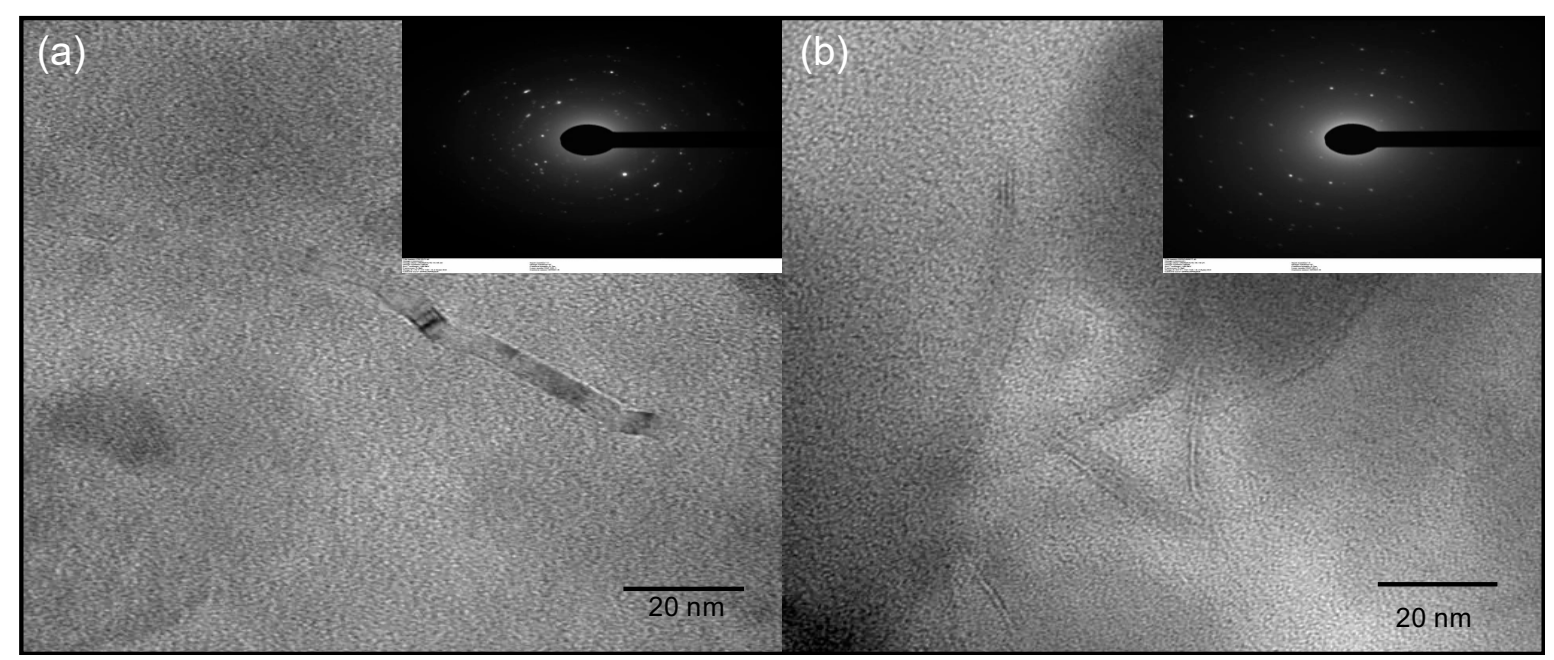

Figure 9. High-magnification BF-TEM micrographs showing structures associated with graphite and graphene, respectively in (a) Cd.CB and (b) $\mathrm{Cd}_{2} \mathrm{H}_{2} \mathrm{SO}_{4}$. The inset figures show the corresponding SAED pattern.

\subsection{Photoluminescence (PL)}

The photoluminescence (PL) of carbon dots is of great interest since many of its applications are based on these properties. Although the mechanism of PL from carbon dots has been extensively studied, the origin of fluorescence is still unknown $[2,25]$. The results of the PL analysis (Figures 10 and 11) revealed differences between the carbon dot samples depending on whether or not their precursor was activated. In comparison to the non-activated sample (Cd.CB), carbon dots from activated precursors showed an obvious bathochromic shift in their PL spectra; $\mathrm{Cd}$.CB had a higher PL intensity; $\mathrm{Cd}$.CB had an excitation-independent behavior, whereas $\mathrm{Cd}_{2} \mathrm{H}_{2} \mathrm{SO}_{4}, \mathrm{Cd} . \mathrm{KOH}$, and $\mathrm{Cd}_{2} \mathrm{H}_{2} \mathrm{SO}_{4}+\mathrm{KOH}$ had an excitation-dependent behavior. All of these differences in the PL properties are analyzed in detail in this study.

It has been reported that carbon dots from pyrolytic carbon black presented a PL peak at $415 \mathrm{~nm}$ at the maximum excitation wavelength $(380 \mathrm{~nm})$ [70]. As can be seen in Figure 10, in our study, a bathochromic shift (shift to longer wavelengths) was observed in all carbon dot samples compared to those reported in the literature. This result could be associated with a higher oxidation degree [71,72].

The PL shift was even higher in the carbon dots from activated precursors (Cd.CB $<$ Cd. $\left.\mathrm{H}_{2} \mathrm{SO}_{4}<\mathrm{Cd} . \mathrm{H}_{2} \mathrm{SO}_{4}+\mathrm{KOH}<\mathrm{Cd} . \mathrm{KOH}\right)$. A hypsochromic or bathochromic shift is caused by a bandgap modification [73-76]. A hypsochromic PL shift is observed with a widening of the bandgap, while the opposite (a bathochromic shift) occurs by narrowing the bandgap [73]. This bandgap is highly dependent on the nanoparticle size and the surface functionalization. The electron delocalization on the carbon structure and electron confinement in the carbon dots causes the bandgap modification caused by the carbon dot's size [71]. Some researchers have shown that the size of carbon dots affects the bandgap and thus the PL emission $[77,78]$. The bandgap, on the other hand, is strongly influenced by surface functionalization with oxygen-containing groups: as the oxygen content increases, the bandgap decreases [79]. Some authors have reported that surface oxidation creates surface defects [76], which serve as capture centers for excitons. Further, the bathochromic shift is caused by the radiation from the recombination of trapped excitons [80]. Therefore, it is well accepted that a higher oxidation degree causes a bathochromic shift $[71,72,75,79]$, while a higher surface oxidation and the creation of surface defects are achieved with the use of strong acids [50,81], such as the $\mathrm{HNO}_{3}$ used in this study. 


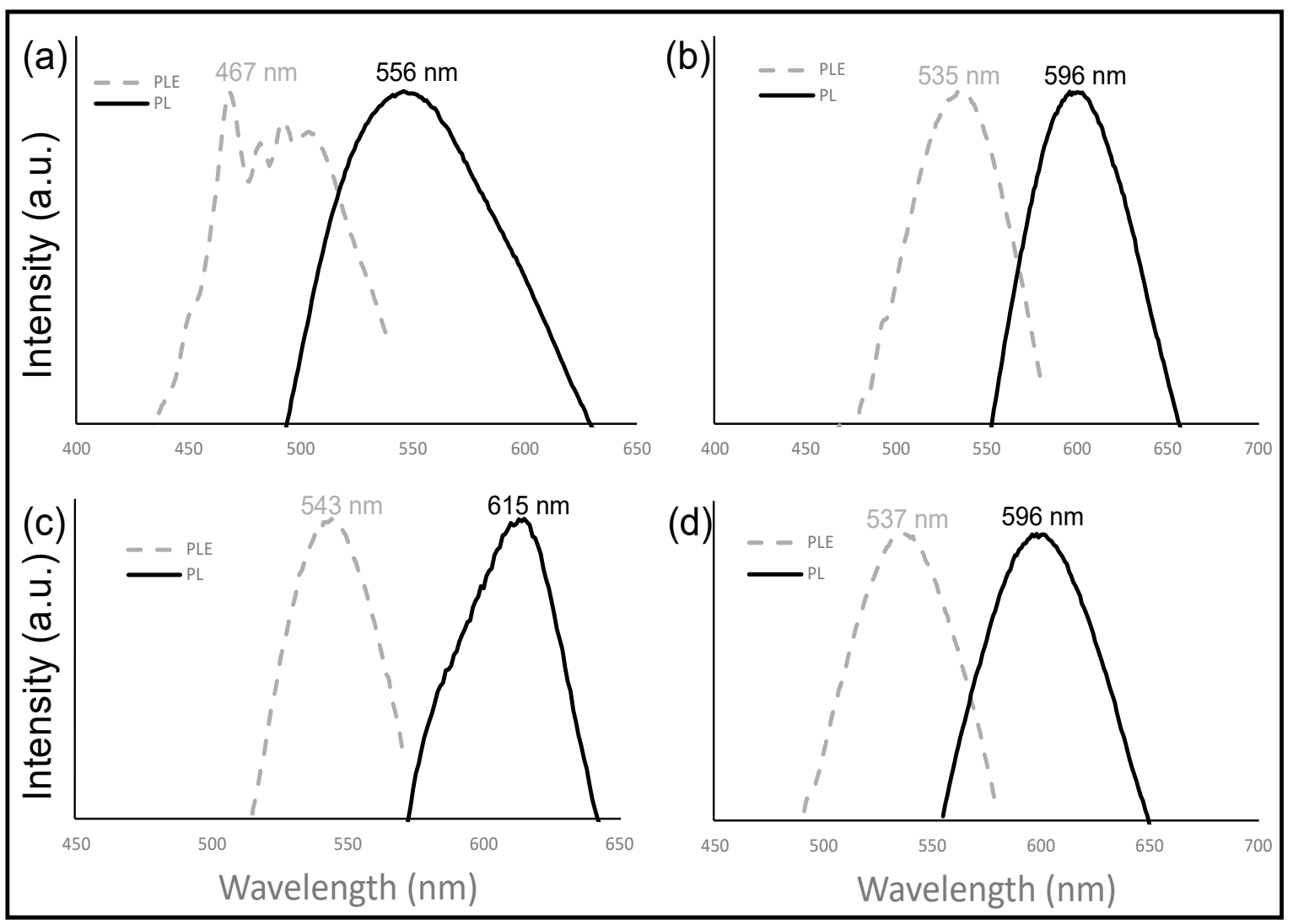

Figure 10. Photoluminescence (PL) and photoluminescence excitation (PLE) spectra of (a) Cd.CB, (b) $\mathrm{Cd} . \mathrm{H}_{2} \mathrm{SO}_{4}$, (c) $\mathrm{Cd} . \mathrm{KOH}$, and (d) $\mathrm{Cd} . \mathrm{H}_{2} \mathrm{SO}_{4}+\mathrm{KOH}$.
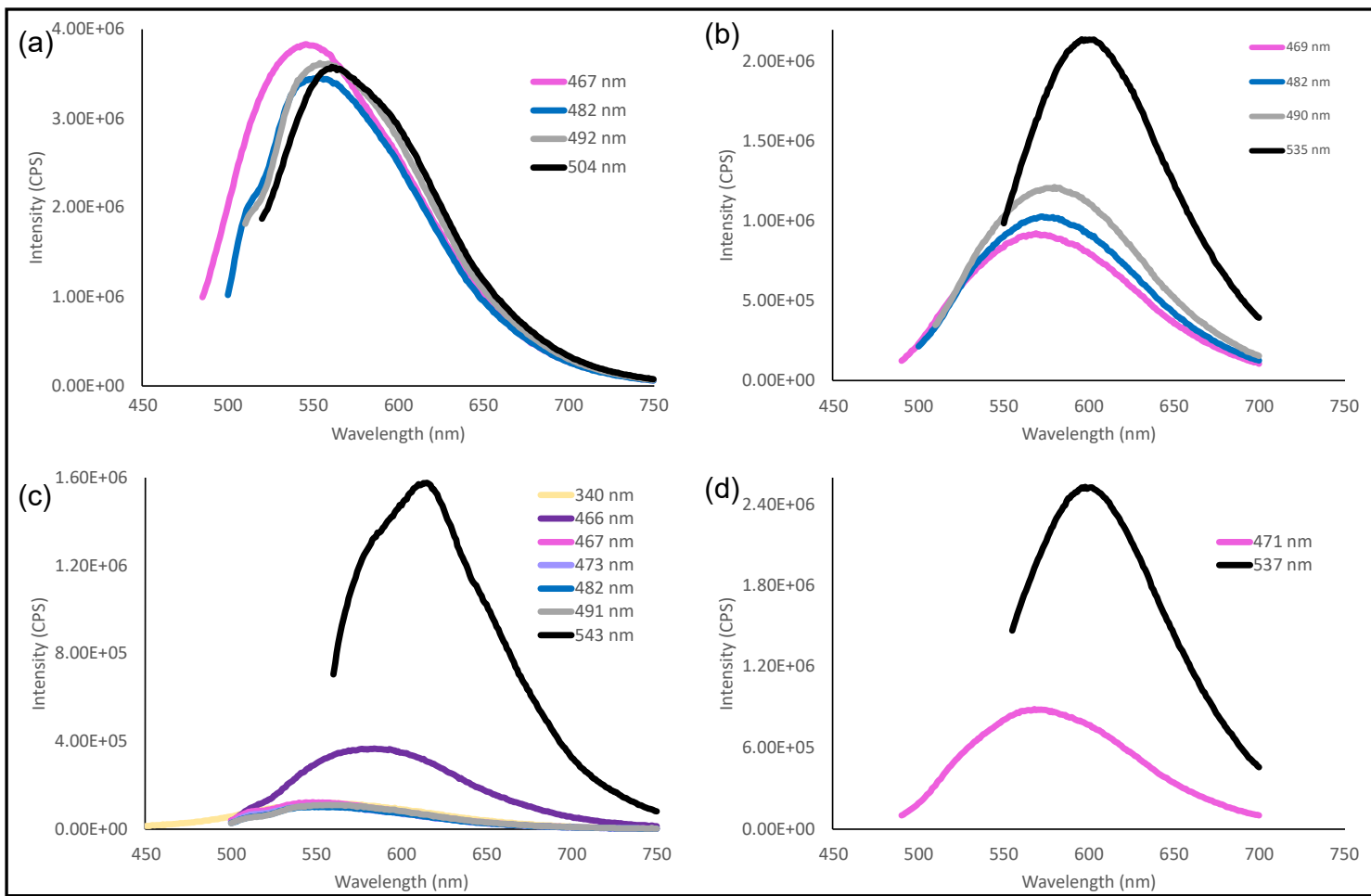

Figure 11. PL spectra at different wavelengths of (a) $\mathrm{Cd} . \mathrm{CB},(\mathbf{b}) \mathrm{Cd}_{2} \mathrm{H}_{2} \mathrm{SO}_{4}$, (c) $\mathrm{Cd} . \mathrm{KOH}$, and (d) $\mathrm{Cd} . \mathrm{H}_{2} \mathrm{SO}_{4}+\mathrm{KOH}$. 
In this context, the observed bathochromic shift in the PL spectra of carbon dots from activated precursors $\left(\mathrm{Cd} . \mathrm{H}_{2} \mathrm{SO}_{4}, \mathrm{Cd} . \mathrm{KOH}\right.$, and $\left.\mathrm{Cd} . \mathrm{H}_{2} \mathrm{SO}_{4}+\mathrm{KOH}\right)$ may be caused by a higher oxidation degree than that presented in Cd.CB. These findings are consistent with XPS and Raman results, which showed that carbon dots from activated samples have a higher functionalization. Carbon dots were made by chemical oxidation with $\mathrm{HNO}_{3}$, which oxidizes the starting material while also introducing oxygen and nitrogen-containing groups to the surface of the carbon dots. [51,75]. We suggest that functional groups were more easily introduced in the carbon surface when the precursor was previously treated with acid or alkali (activated carbon). Abdel-Nasser and El-Hendawy [51], observed an increase in the oxygen, hydrogen, and nitrogen content when oxidation with $\mathrm{HNO}_{3}$ was performed on activated carbon compared with the corresponding non-oxidized char. Other researchers [82,83] found similar results, attributing the higher functionalization by wet oxidation to a larger surface area with more developed textures on the activated carbons. A greater surface area provides a better precursor- $\mathrm{HNO}_{3}$ contact, thus enhancing the reactions and introducing more functional groups.

A higher oxidation degree on carbon dots from activated precursors was also demonstrated with the results provided by XPS and Raman spectroscopy [56]. Besides the oxidation degree effect, the presence of nitro groups may induce an additional bathochromic shift on the PL because of the electron-accepting effect from the nitro functional group $[75,84,85]$.

Carbon dots from activated precursors $\left(\mathrm{Cd} . \mathrm{H}_{2} \mathrm{SO}_{4}, \mathrm{Cd} . \mathrm{KOH}\right.$, and $\left.\mathrm{Cd} . \mathrm{H}_{2} \mathrm{SO}_{4}+\mathrm{KOH}\right)$ showed an excitation-dependent behavior. Figure 11b-d show that the abundant functional groups on the surface of carbon dots from activated precursors, as well as the resulting surface defects, may play a role in the excitation-dependent behavior. The heterogeneity of carbon dots [86], as a result of the introduction of surface defects by functional groups with various energy levels $[87,88]$, has been reported to be the source of the excitation-dependent behavior. In particular, oxygen-containing groups have a strong effect on the creation of energy gaps that result in a tunable PL [89]. This tunable emission is important in understanding the electronic states of carbon dots and for various applications, such as biosensing, allowing simultaneous monitoring of various analytes and processes [90] and optoelectrical applications [91]. On the other hand, the emission behavior observed on the carbon dots from the nonactivated precursor (Cd.CB) might be optimal for applications such as fluorescence ink and as a fluorescent sensor for the detection of metallic ions in aqueous solution [86].

Regarding PL intensity, the Cd.CB sample exhibited a different behavior to carbon dots from activated precursors (Figure 11). Carbon dots from activated precursors showed a greater intensity as the excitation wavelength increased, with a maximum value in the range of 535-543 nm; the opposite was observed in Cd.CB, with a maximum PL intensity of $467 \mathrm{~nm}$. Moreover, the PL intensity of Cd.CB is considerably greater than any of the other carbon dot samples (Figure 11a). It has been reported that the oxidation degree of the carbon dots, in addition to the bathochromic shift, has an effect on emission intensity [72]. This effect is due to the surface traps acting as nonradiative recombination centers, which can decrease the PL intensity [92,93]. In addition, the presence of electron-withdrawing groups such as nitro groups causes a decrease in the PL intensity [94]. Therefore, the synthesized carbon dots from activated precursors are rich in oxygen-containing groups and nitrogencontaining groups on their surface as demonstrated by XPS and Raman techniques, which causes its hydrophilicity, negative $\zeta$ potential, bathochromic shift, excitation-dependent behavior, and PL intensity decrease.

\section{Conclusions}

In this study, the dialysis purification process was carefully analyzed by ion chromatography, concluding that $360 \mathrm{~h}$ were required to completely purify the carbon dots synthesized from pyrolytic carbon black from waste tires by a chemical oxidation method. It was shown that carbon dots could be made from carbon black and activated carbon black. However, whether the precursor was activated or not, some differences in their 
PL properties were discovered: the region of the electromagnetic spectrum where the PL emission occurred, the intensity of the PL emission, and the excitation-dependent behavior. In addition, some differences in their carbon core were observed; carbon dots synthesized from the $\mathrm{H}_{2} \mathrm{SO}_{4}$ - activated precursor exhibited a higher crystallinity (graphitized domains) than carbon dots from non-activated precursor and basic-activated precursor.

The obtained $\zeta$ potential, UV-visible, FTIR, and Raman spectra indicated the presence of functional groups such as carboxyl, hydroxyl, and nitro groups in the four synthesized carbon dots. However, carbon dots from activated precursors presented an increase in the ID/IG, suggesting a higher content of surface functional groups. The increase in the functional groups and the high oxidation degree caused a bathochromic shift in their PL spectra with an excitation-dependent behavior, contrary to the behavior observed in Cd.CB (carbon dots from non-activated precursor). Although the PL mechanism is still unknown, it is reasonable to believe that the chemical composition and surface morphology of the precursor influence the optical properties of carbon dots due to the better attachment of surface functional groups during chemical oxidation with $\mathrm{HNO}_{3}$. Understanding the observed differences in the optical properties of carbon dots is essential for suggesting their possible applications.

Author Contributions: Investigation and methodology, R.B.G.-G., L.T.G., A.M. and C.L.-P.; Supervision, M.M., S.O.M.-C., L.T.G. and A.M.; Writing and original draft preparation, R.B.G.-G. and A.M.; funding acquisition, A.M. All authors have read and agreed to the published version of the manuscript.

Funding: This study is a product of the Project 266632 "Laboratorio Binacional para la Gestión Inteligente de la Sustentabilidad Energética y Formación Tecnológica" funded by the CONACYT SENER Fund for Energy Sustainability (agreement: S0019 201401). R.B. González-González acknowledges the support received by Mexico's CONACYT. The use of the TEM at the facilities of the Laboratorio Nacional de Nanotecnología (Nanotech) and the support provided by M.S. Raúl Ochoa are also acknowledged.

Institutional Review Board Statement: Not applicable.

Informed Consent Statement: Not applicable.

Data Availability Statement: The data presented in this study are available on request from the corresponding author.

Conflicts of Interest: The authors declare no conflict of interest.

\section{References}

1. Xu, X.; Ray, R.; Gu, Y.; Ploehn, H.J.; Gearheart, L.; Raker, K.; Scrivens, W.A. Electrophoretic analysis and purification of fluorescent single-walled carbon nanotube fragments. J. Am. Chem. Soc. 2004, 126, 12736-12737. [CrossRef]

2. Wang, R.; Lu, K.Q.; Tang, Z.R.; Xu, Y.J. Recent progress in carbon quantum dots: Synthesis, properties and applications in photocatalysis. J. Mater. Chem. A 2017, 5, 3717-3734. [CrossRef]

3. Yan, F.; Sun, Z.; Zhang, H.; Sun, X.; Jiang, Y.; Bai, Z. The fluorescence mechanism of carbon dots, and methods for tuning their emission color: A review. Microchim. Acta 2019, 186, 583. [CrossRef] [PubMed]

4. Chatzimitakos, T.; Stalikas, C. Recent Advances in Carbon Dots. C 2019, 5, 41. [CrossRef]

5. Wang, Y.; Hu, A. Carbon quantum dots: Synthesis, properties and applications. J. Mater. Chem. C Mater. Opt. Electron. Devices 2014, 2, 6921-6939. [CrossRef]

6. Xu, M.; He, G.; Li, Z.; He, F.; Gao, F.; Su, Y.; Zhang, L.; Yang, Z.; Zhang, Y. A green heterogeneous synthesis of N-doped carbon dots and their photoluminescence applications in solid and aqueous states. Nanoscale 2014, 6, 10307-10315. [CrossRef]

7. Atabaev, T.S. Doped carbon dots for sensing and bioimaging applications: A minireview. Nanomaterials $2018,8,342$. [CrossRef] [PubMed]

8. Brabazon, D.; Pellicer, E.; Zivic, F.; Sort, J.; Baró, M.D.; Grujovic, N.; Choy, K.L. Commercialization of Nanotechnologies—A Case Study Approach; Springer: Berlin/Heidelberg, Germany, 2017; pp. 1-315.

9. Hoang, V.C.; Hassan, M.; Gomes, V.G. Coal derived carbon nanomaterials-Recent advances in synthesis and applications. Appl. Mater. Today 2018, 12, 342-358. [CrossRef]

10. Deng, J.; You, Y.; Sahajwalla, V.; Joshi, R.K. Transforming waste into carbon-based nanomaterials. Carbon N. Y. 2016, 96, 105-115. [CrossRef] 
11. Gómez-Hernández, R.; Panecatl-Bernal, Y.; Méndez-Rojas, M.Á. High yield and simple one-step production of carbon black nanoparticles from waste tires. Heliyon 2019, 5, e02139. [CrossRef]

12. Tang, L.; Ji, R.; Cao, X.; Lin, J.; Jiang, H.; Li, X.; Teng, K.S.; Luk, C.M.; Zeng, S.; Hao, J.; et al. Deep ultraviolet photoluminescence of water-soluble self-passivated graphene quantum dots. ACS Nano 2012, 6, 5102-5110. [CrossRef] [PubMed]

13. Oztan, C.Y.; Hamawandi, B.; Zhou, Y.; Ballikaya, S.; Toprak, M.S.; Leblanc, R.M.; Coverstone, V.; Celik, E. Thermoelectric performance of $\mathrm{Cu}_{2} \mathrm{Se}$ doped with rapidly synthesized gel-like carbon dots. J. Alloys Compd. 2021, 864, 157916. [CrossRef]

14. Sathiskumar, C.; Karthikeyan, S. Recycling of waste tires and its energy storage application of by-products-A review. Sustain. Mater. Technol. 2019, 22, e00125. [CrossRef]

15. Alsaleh, A.; Sattler, M.L. Waste Tire Pyrolysis: Influential Parameters and Product Properties. Curr. Sustain. Energy Rep. 2014, 1, 129-135. [CrossRef]

16. Hadi, P.; Yeung, K.Y.; Guo, J.; Wang, H.; McKay, G. Sustainable development of tyre char-based activated carbons with different textural properties for value-added applications. J. Environ. Manag. 2016, 170, 1-7. [CrossRef]

17. Li, S.Q.; Yao, Q.; Wen, S.E.; Chi, Y.; Yan, J.H. Properties of pyrolytic chars and activated carbons derived from pilot-scale pyrolysis of used tires. J. Air Waste Manag. Assoc. 2005, 55, 1315-1326. [CrossRef]

18. Martínez, J.D.; Cardona-Uribe, N.; Murillo, R.; García, T.; López, J.M. Carbon black recovery from waste tire pyrolysis by demineralization: Production and application in rubber compounding. Waste Manag. 2019, 85, 574-584. [CrossRef]

19. Nieto-Márquez, A.; Atanes, E.; Morena, J.; Fernández-Martínez, F.; Valverde, J.L. Upgrading waste tires by chemical activation for the capture of SO2. Fuel Process. Technol. 2016, 144, 274-281. [CrossRef]

20. Aranda, A.; Murillo, R.; García, T.; Callén, M.S.; Mastral, A.M. Steam activation of tyre pyrolytic carbon black: Kinetic study in a thermobalance. Chem. Eng. J. 2007, 126, 79-85. [CrossRef]

21. Teng, H.; Lin, Y.C.; Hsu, L.Y. Production of activated carbons from pyrolysis of waste tires impregnated with potassium hydroxide. J. Air Waste Manag. Assoc. 2000, 50, 1940-1946. [CrossRef]

22. Shilpa; Kumar, R.; Sharma, A. Morphologically tailored activated carbon derived from waste tires as high-performance anode for Li-ion battery. J. Appl. Electrochem. 2018, 48, 1-13. [CrossRef]

23. Kumar, R.; Bhuvana, T.; Sharma, A. Tire Waste Derived Turbostratic Carbon as an Electrode for a Vanadium Redox Flow Battery. ACS Sustain. Chem. Eng. 2018, 6, 8238-8246. [CrossRef]

24. Naskar, A.K.; Bi, Z.; Li, Y.; Akato, S.K.; Saha, D.; Chi, M.; Bridges, C.A.; Paranthaman, M.P. Tailored recovery of carbons from waste tires for enhanced performance as anodes in lithium-ion batteries. RSC Adv. 2014, 4, 38213. [CrossRef]

25. Liu, M.L.; Chen, B.B.; Li, C.M.; Huang, C.Z. Carbon dots: Synthesis, formation mechanism, fluorescence origin and sensing applications. Green Chem. 2019, 21, 449-471. [CrossRef]

26. Crista, D.M.A.; da Silva, J.C.G.E.; da Silva, L.P. Evaluation of different bottom-up routes for the fabrication of carbon dots Nanomaterials 2020, 10, 1316. [CrossRef]

27. Papaioannou, N.; Titirici, M.M.; Sapelkin, A. Investigating the Effect of Reaction Time on Carbon Dot Formation, Structure, and Optical Properties. ACS Omega 2019, 4, 21658-21665. [CrossRef] [PubMed]

28. Mozdbar, A.; Nouralishahi, A.; Fatemi, S.; Mirakhori, G. The effect of precursor on the optical properties of carbon quantum dots synthesized by hydrothermal/solvothermal method. AIP Conf. Proc. 2018, 1920, 020029.

29. Chen, C.Y.; Tsai, Y.H.; Chang, C.W. Evaluation of the dialysis time required for carbon dots by HPLC and the properties of carbon dots after HPLC fractionation. New J. Chem. 2019, 43, 6153-6159. [CrossRef]

30. Essner, J.B.; Kist, J.A.; Polo-Parada, L.; Baker, G.A. Artifacts and Errors Associated with the Ubiquitous Presence of Fluorescent Impurities in Carbon Nanodots. Chem. Mater. 2018, 30, 1878-1887. [CrossRef]

31. Hinterberger, V.; Damm, C.; Haines, P.; Guldi, D.M.; Peukert, W. Purification and structural elucidation of carbon dots by column chromatography. Nanoscale 2019, 11, 8464-8474. [CrossRef]

32. Zobir, S.A.M.; Rashid, S.A.; Tan, T. Recent Development on the Synthesis Techniques and Properties of Graphene Derivatives; Elsevier Inc.: Cambridge, UK, 2018

33. González-González, R.; González, L.T.; Iglesias-González, S.; González-González, E.; Martinez-Chapa, S.O.; Madou, M.; Alvarez, M.; Mendoza, A. Characterization of Chemically Activated Pyrolytic Carbon Black Derived from Waste Tires as a Candidate for Nanomaterial Precursor. Nanomaterials 2020, 10, 2213. [CrossRef]

34. Dong, Y.; Zhou, N.; Lin, X.; Lin, J.; Chi, Y.; Chen, G. Extraction of electrochemiluminescent oxidized carbon quantum dots from activated carbon. Chem. Mater. 2010, 22, 5895-5899. [CrossRef]

35. Khan, W.U.; Wang, D.; Zhang, W.; Tang, Z.; Ma, X.; Ding, X.; Du, S.; Wang, Y. High quantum yield green-emitting carbon dots for Fe(III) detection, biocompatible fluorescent ink and cellular imaging. Sci. Rep. 2017, 7, 14866. [CrossRef] [PubMed]

36. Qu, S.; Wang, X.; Lu, Q.; Liu, X.; Wang, L. A Biocompatible Fluorescent Ink Based on Water-Soluble Luminescent Carbon Nanodots. Angew. Chem. 2012, 124, 12381-12384. [CrossRef]

37. Yang, W.; Zhang, H.; Lai, J.; Peng, X.; Hu, Y.; Gu, W.; Ye, L. Carbon dots with red-shifted photoluminescence by fluorine doping for optical bio-imaging. Carbon N. Y. 2018, 128, 78-85. [CrossRef]

38. Lin, S.; Lin, C.; He, M.; Yuan, R.; Zhang, Y.; Zhou, Y.; Xiang, W.; Liang, X. Solvatochromism of bright carbon dots with tunable long-wavelength emission from green to red and their application as solid-state materials for warm WLEDs. RSC Adv. 2017, 7, 41552-41560. [CrossRef] 
39. Nie, H.; Li, M.; Li, Q.; Liang, S.; Tan, Y.; Sheng, L.; Shi, W.; Zhang, S.X.A. Carbon dots with continuously tunable full-color emission and their application in ratiometric pH sensing. Chem. Mater. 2014, 26, 3104-3112. [CrossRef]

40. Kim, K.; Chokradjaroen, C.; Saito, N. Solution plasma: New synthesis method of N-doped carbon dots as ultra-sensitive fluorescence detector for 2,4,6-trinitrophenol. Nano Express 2020, 1, 020043. [CrossRef]

41. Baweja, H.; Jeet, K. Economical and green synthesis of graphene and carbon quantum dots from agricultural waste. Mater. Res. Express 2019, 6, 0850g8. [CrossRef]

42. Guo, L.; Zhang, Y.; Ruo-Xi, Z. A Simple and Practical Synthetic Method of Carbon Quantum Dots. Asian J. Chem. 2014, 26, 70-73. [CrossRef]

43. Gupta, A.; Verma, N.C.; Khan, S.; Nandi, C.K. Carbon dots for naked eye colorimetric ultrasensitive arsenic and glutathione detection. Biosens. Bioelectron. 2016, 81, 465-472. [CrossRef] [PubMed]

44. Qiang, R.; Yang, S.; Hou, K.; Wang, J. Synthesis of carbon quantum dots with green luminescence from potato starch. New J. Chem. 2019, 43, 10826-10833. [CrossRef]

45. Xu, H.; Yang, X.; Li, G.; Zhao, C.; Liao, X. Green Synthesis of Fluorescent Carbon Dots for Selective Detection of Tartrazine in Food Samples. J. Agric. Food Chem. 2015, 63, 6707-6714. [CrossRef]

46. Xu, Q.; Pu, P.; Zhao, J.; Dong, C.; Gao, C.; Chen, Y.; Chen, J.; Liu, Y.; Zhou, H. Preparation of highly photoluminescent sulfur-doped carbon dots for Fe(iii) detection. J. Mater. Chem. A 2015, 3, 542-546. [CrossRef]

47. Zhong, Q.; Chen, Y.; Su, A.; Wang, Y. Synthesis of catalytically active carbon quantum dots and its application for colorimetric detection of glutathione. Sens. Actuators B Chem. 2018, 273, 1098-1102. [CrossRef]

48. Pooja, D.; Saini, S.; Thakur, A.; Kumar, B.; Tyagi, S.; Nayak, M.K. A “Turn-On” thiol functionalized fluorescent carbon quantum dot based chemosensory system for arsenite detection. J. Hazard. Mater. 2017, 328, 117-126.

49. Zhang, C.; Song, W.; Sun, G.; Xie, L.; Wang, J.; Li, K.; Sun, C.; Liu, H.; Snape, C.E.; Drage, T. CO 2 capture with activated carbon grafted by nitrogenous functional groups. Energy Fuels 2013, 27, 4818-4823. [CrossRef]

50. Datsyuk, V.; Kalyva, M.; Papagelis, K.; Parthenios, J.; Tasis, D.; Siokou, A.; Kallitsis, I.; Galiotis, C. Chemical oxidation of multiwalled carbon nanotubes. Carbon N. Y. 2008, 46, 833-840. [CrossRef]

51. El-Hendawy, A.N.A. Influence of $\mathrm{HNO}_{3}$ oxidation on the structure and adsorptive properties of corncob-based activated carbon. Carbon N. Y. 2003, 41, 713-722. [CrossRef]

52. Moreno-Castilla, C.; López-Ramón, M.V.; Carrasco-Marín, F. Changes in surface chemistry of activated carbons by wet oxidation Carbon N. Y. 2000, 38, 1995-2001. [CrossRef]

53. Chingombe, P.; Saha, B.; Wakeman, R.J. Surface modification and characterisation of a coal-based activated carbon. Carbon N. Y. 2005, 43, 3132-3143. [CrossRef]

54. Salame, I.I.; Bandosz, T.J. Surface chemistry of activated carbons: Combining the results of temperature-programmed desorption, Boehm, and potentiometric titrations. J. Colloid Interface Sci. 2001, 240, 252-258. [CrossRef]

55. Houshmand, A.; Daud, W.M.A.W.; Shafeeyan, M.S. Exploring potential methods for anchoring amine groups on the surface of activated carbon for $\mathrm{CO}_{2}$ adsorption. Sep. Sci. Technol. 2011, 46, 1098-1112. [CrossRef]

56. Krishnamoorthy, K.; Veerapandian, M.; Yun, K.; Kim, S.J. The chemical and structural analysis of graphene oxide with different degrees of oxidation. Carbon. N. Y. 2013, 53, 38-49. [CrossRef]

57. Bokobza, L.; Bruneel, J.-L.; Couzi, M. Raman Spectra of Carbon-Based Materials (from Graphite to Carbon Black) and of Some Silicone Composites. C-J. Carbon Res. 2015, 1, 77-94. [CrossRef]

58. Wu, J.; Wang, P.; Wang, F.; Fang, Y. Investigation of the microstructures of graphene quantum dots (GQDs) by surface-enhanced Raman spectroscopy. Nanomaterials 2018, 8, 864. [CrossRef] [PubMed]

59. Bayati, M.; Dai, J.; Zambrana, A.; Rees, C.; Fidalgo de Cortalezzi, M. Effect of water chemistry on the aggregation and photoluminescence behavior of carbon dots. J. Environ. Sci. 2018, 65, 223-235. [CrossRef]

60. Radhakrishnan, K.; Panneerselvam, P.; Marieeswaran, M. A green synthetic route for the surface-passivation of carbon dots as an effective multifunctional fluorescent sensor for the recognition and detection of toxic metal ions from aqueous solution. Anal. Methods 2019, 11, 490-506. [CrossRef]

61. Radhakrishnan, K.; Sivanesan, S.; Panneerselvam, P. Turn-On fluorescence sensor based detection of heavy metal ion using carbon dots@graphitic-carbon nitride nanocomposite probe. J. Photochem. Photobiol. A Chem. 2020, 389, 112204. [CrossRef]

62. Pudza, M.Y.; Abidin, Z.Z.; Rashid, S.A.; Yasin, F.M.; Noor, A.S.M.; Issa, M.A. Eco-friendly sustainable fluorescent carbon dots for the adsorption of heavy metal ions in aqueous environment. Nanomaterials 2020, 10, 315. [CrossRef]

63. Chen, G.; Wu, S.; Hui, L.; Zhao, Y.; Ye, J.; Tan, Z.; Zeng, W.; Tao, Z.; Yang, L.; Zhu, Y. Assembling carbon quantum dots to a layered carbon for high-density supercapacitor electrodes. Sci. Rep. 2016, 6, 19028. [CrossRef]

64. Varisco, M.; Zufferey, D.; Ruggi, A.; Zhang, Y.; Erni, R.; Mamula, O. Synthesis of hydrophilic and hydrophobic carbon quantum dots from waste of wine fermentation. R. Soc. Open Sci. 2017, 4, 170900. [CrossRef] [PubMed]

65. Hagiwara, K.; Uchida, H.; Suzuki, Y.; Hayashita, T.; Torigoe, K.; Kida, T.; Horikoshi, S. Role of alkan-1-ol solvents in the synthesis of yellow luminescent carbon quantum dots (CQDs): Van der Waals force-caused aggregation and agglomeration. RSC Adv. 2020, 10, 14396-14402. [CrossRef]

66. Pimenta, M.A.; Dresselhaus, G.; Dresselhaus, M.S.; Cançado, L.G.; Jorio, A.; Saito, R. Studying disorder in graphite-based systems by Raman spectroscopy. Phys. Chem. Chem. Phys. 2007, 9, 1276-1291. [CrossRef] 
67. Banna Motejadded Emrooz, H.; Maleki, M.; Shokouhimehr, M. Excellent adsorption of orange acid II on a water fern-derived micro- and mesoporous carbon. J. Taiwan Inst. Chem. Eng. 2019, 102, 99-109. [CrossRef]

68. Li, J.L.; Kudin, K.N.; McAllister, M.J.; Prud'homme, R.K.; Aksay, I.A.; Car, R. Oxygen-driven unzipping of graphitic materials. Phys. Rev. Lett. 2006, 96, 5-8. [CrossRef]

69. Wang, G.; Wang, B.; Park, J.; Yang, J.; Shen, X.; Yao, J. Synthesis of enhanced hydrophilic and hydrophobic graphene oxide nanosheets by a solvothermal method. Carbon N. Y. 2009, 47, 68-72. [CrossRef]

70. Parra, J.; Silva, K.; Valezin, P.; Martins, R.; Gomes, R.; Pereira, R.; de Melo, F.; Morandim-Giannetti, A.; dos Santos, R.; Panzarini, L.C.; et al. Preparation of Fluorescent Carbon-Based Dots from Waste Tire Pyrolysis. J. Braz. Chem. Soc. 2020, 31, 2224-2231. [CrossRef]

71. Barman, M.K.; Patra, A. Current status and prospects on chemical structure driven photoluminescence behaviour of carbon dots. J. Photochem. Photobiol. C Photochem. Rev. 2018, 37, 1-22. [CrossRef]

72. Zheng, H.; Wang, Q.; Long, Y.; Zhang, H.; Huang, X.; Zhu, R. Enhancing the luminescence of carbon dots with a reduction pathway. Chem. Commun. 2011, 47, 10650-10652. [CrossRef] [PubMed]

73. Noor-UI-Ain; Eriksson, M.O.; Schmidt, S.; Asghar, M.; Lin, P.C.; Holtz, P.O.; Syväjärvi, M.; Reza Yazdi, G. Tuning the emission energy of chemically doped graphene quantum dots. Nanomaterials 2016, 6, 198. [CrossRef]

74. Jin, S.H.; Kim, D.H.; Jun, G.H.; Hong, S.H.; Jeon, S. Tuning the photoluminescence of graphene quantum dots through the charge transfer effect of functional groups. ACS Nano 2013, 7, 1239-1245. [CrossRef]

75. Zhao, M. Direct Synthesis of Graphene Quantum Dots with Different Fluorescence Properties by Oxidation of Graphene Oxide Using Nitric Acid. Appl. Sci. 2018, 8, 1303. [CrossRef]

76. Bao, L.; Liu, C.; Zhang, Z.L.; Pang, D.W. Photoluminescence-tunable carbon nanodots: Surface-state energy-gap tuning. Adv. Mater. 2015, 27, 1663-1667. [CrossRef] [PubMed]

77. Ye, R.; Peng, Z.; Metzger, A.; Lin, J.; Mann, J.A.; Huang, K.; Xiang, C.; Fan, X.; Samuel, E.L.G.; Alemany, L.B.; et al. Bandgap engineering of coal-derived graphene quantum dots. ACS Appl. Mater. Interfaces 2015, 7, 7041-7048. [CrossRef]

78. Yeh, T.F.; Huang, W.L.; Chung, C.J.; Chiang, I.T.; Chen, L.C.; Chang, H.Y.; Su, W.C.; Cheng, C.; Chen, S.J.; Teng, H. Elucidating Quantum Confinement in Graphene Oxide Dots Based on Excitation-Wavelength-Independent Photoluminescence. J. Phys. Chem. Lett. 2016, 7, 2087-2092. [CrossRef]

79. Ding, H.; Yu, S.B.; Wei, J.S.; Xiong, H.M. Full-color light-emitting carbon dots with a surface-state-controlled luminescence mechanism. ACS Nano 2016, 10, 484-491. [CrossRef] [PubMed]

80. Bao, L.; Zhang, Z.L.; Tian, Z.Q.; Zhang, L.; Liu, C.; Lin, Y.; Qi, B.; Pang, D.W. Electrochemical tuning of luminescent carbon nanodots: From preparation to luminescence mechanism. Adv. Mater. 2011, 23, 5801-5806. [CrossRef]

81. Li, L.; Dong, T. Photoluminescence tuning in carbon dots: Surface passivation or/and functionalization, heteroatom doping. $J$. Mater. Chem. C 2018, 6, 7944-7970. [CrossRef]

82. Moreno-Castilla, C.; Carrasco-Marín, F.; Mueden, A. The creation of acid carbon surfaces by treatment with $\left(\mathrm{NH}_{4}\right)_{2} \mathrm{~S}_{2} \mathrm{O}_{8}$. Carbon N. Y. 1997, 35, 1619-1626. [CrossRef]

83. Álvarez-Merino, M.A.; López-Ramón, V.; Moreno-Castilla, C. A study of the static and dynamic adsorption of Zn(II) ions on carbon materials from aqueous solutions. J. Colloid Interface Sci. 2005, 288, 335-341. [CrossRef]

84. Wu, M.; Zhan, J.; Geng, B.; He, P.; Wu, K.; Wang, L.; Xu, G.; Li, Z.; Yin, L.; Pan, D. Scalable synthesis of organic-soluble carbon quantum dots: Superior optical properties in solvents, solids, and LEDs. Nanoscale 2017, 9, 13195-13202. [CrossRef]

85. Choi, J.; Kim, N.; Oh, J.W.; Kim, F.S. Bandgap engineering of nanosized carbon dots through electron-accepting functionalization J. Ind. Eng. Chem. 2018, 65, 104-111. [CrossRef]

86. Wen, Z.H.; Yin, X.B. Excitation-independent carbon dots, from photoluminescence mechanism to single-color application. RSC Adv. 2016, 6, 27829-27835. [CrossRef]

87. Zhao, Y.; Liu, X.; Yang, Y.; Kang, L.; Yang, Z.; Liu, W.; Chen, L. Carbon Dots: From Intense Absorption in Visible Range to ExcitationIndependent and Excitation-Dependent Photoluminescence. Fuller. Nanotub. Carbon Nanostr. 2015, 23, 922-929. [CrossRef]

88. Dong, Y.; Pang, H.; Ren, S.; Chen, C.; Chi, Y.; Yu, T. Etching single-wall carbon nanotubes into green and yellow single-layer graphene quantum dots. Carbon N. Y. 2013, 64, 245-251. [CrossRef]

89. Hu, S.; Trinchi, A.; Atkin, P.; Cole, I. Tunable photoluminescence across the entire visible spectrum from carbon dots excited by white light. Angew. Chem.-Int. Ed. 2015, 54, 2970-2974. [CrossRef]

90. Demchenko, A. Excitons in Carbonic Nanostructures. C 2019, 5, 71. [CrossRef]

91. Mishra, K.; Koley, S.; Ghosh, S. Ground-State Heterogeneity along with Fluorescent Byproducts Causes Excitation-Dependent Fluorescence and Time-Dependent Spectral Migration in Citric Acid-Derived Carbon Dots. J. Phys. Chem. Lett. 2019, 10, 335-345. [CrossRef]

92. Xu, Y.; Wu, M.; Feng, X.Z.; Yin, X.B.; He, X.W.; Zhang, Y.K. Reduced carbon dots versus oxidized carbon dots: Photo- and electrochemiluminescence investigations for selected applications. Chem.-A Eur. J. 2013, 19, 6282-6288. [CrossRef]

93. Tang, J.; Zhang, J.; Zhang, Y.; Xiao, Y.; Shi, Y.; Chen, Y.; Ding, L.; Xu, W. Influence of Group Modification at the Edges of Carbon Quantum Dots on Fluorescent Emission. Nanoscale Res. Lett. 2019, 14, 241. [CrossRef] [PubMed]

94. Han, S.; Chang, T.; Zhao, H.; Du, H.; Liu, S.; Wu, B.; Qin, S. Cultivating fluorescent flowers with highly luminescent carbon dots fabricated by a double passivation method. Nanomaterials 2017, 7, 176. [CrossRef] [PubMed] 